\title{
MODELAGEM DE EROSÃO E APORTE DE SEDIMENTOS EM BACIA HIDROGRÁFICA COM O MODELO WaTEM/SEDEM
}

\author{
Julio Cesar Demarchi \\ Doutor em Geografia pela Faculdade de Ciências e Tecnologia \\ Universidade Estadual Paulista "Júlio de Mesquita Filho" - UNESP, Câmpus de Presidente Prudente, SP, Brasil \\ julio.demarchi@unesp.br \\ Edson Luís Piroli \\ Professor Associado III \\ Universidade Estadual Paulista "Júlio de Mesquita Filho" - UNESP, Câmpus de Ourinhos, SP, Brasil \\ edson.piroli@unesp.br
}

\section{RESUMO}

O trabalho objetivou calibrar o modelo WaTEM/SEDEM e simular processos de erosão, deposição e aporte de sedimentos no exutório da bacia hidrográfica do Ribeirão São Domingos, Santa Cruz do Rio Pardo - SP, em chuvas intensas nas condições de uso da terra do ano 2018 e no cenário de adequação do uso à legislação florestal brasileira (LF). Os fatores da Equação Universal de Perda de Solo Revisada, componente de erosão do modelo, foram determinados e mapeados. A partir dos dados pluviométricos, fluviométricos e sedimentométricos de chuvas reais, o modelo foi calibrado e aplicado às condições analisadas. Houve redução das perdas de solo por erosão e do aporte de sedimentos no exutório e o aumento da deposição de sedimentos na bacia no cenário LF em relação a 2018 devido ao aumento da cobertura vegetal, práticas conservacionistas, eficiência de retenção de sedimentos e conectividade das parcelas, que promoveram a redução do fator topográfico. Os resultados indicam a necessidade da análise conjunta dos fatores do meio físico, da estrutura hidrológica e da paisagem das bacias e do uso da terra nestes estudos. A modelagem de erosão em eventos individuais de chuvas mostrou-se promissora para pesquisas no Brasil, cujos solos são altamente suscetíveis à erosão.
\end{abstract}

Palavras-chave: Conservação do Solo. Uso e manejo do solo. Modelos de erosão. Estrutura da paisagem.

\section{MODELING OF SOIL EROSION AND SEDIMENT YIELD IN A WATERSHED USING THE WaTEM/SEDEM MODEL}

\begin{abstract}
The paper aimed to calibrate the WaTEM/SEDEM model and to simulate erosion, sediment deposition, and sediment yield at the outlet of the São Domingos stream watershed, municipality of Santa Cruz do Rio Pardo, São Paulo state, as a result of heavy rainfall events, considering land use conditions in 2018 and the scenario of land use adequacy to the Brazilian Forest Laws (FL). We determined and mapped the factors of the Revised Universal Soil Loss Equation, the erosion component of the model. Using rainfall, discharge and sedimentometric data from real rainfall events, we calibrated and applied the model to the conditions analyzed. There was a reduction in soil loss and sediment yield at the watershed outlet and an increase in sediment deposition in the watershed in FL scenario if compared to 2018, due to the increase in forests, soil conservation techniques, sediment trap efficiency, and parcel connectivity, which promoted the reduction of the topographic factor. The results show the need for a joint analysis of physical environmental factors, watersheds' hydrological and landscape structures, and land use in these studies. The erosion modeling in single rainfall events has shown promising for research in Brazil, whose soils are highly prone to erosion.
\end{abstract}

Keywords: Soil conservation. Land use and management. Erosion models. Landscape structure. 


\section{INTRODUÇÃO}

A erosão do solo, intensificada pela ocupação antrópica, tem como consequências a redução da fertilidade do solo e deterioração das áreas agrícolas, o assoreamento e a contaminação de rios e lagos pelo material erodido e pelos defensivos agrícolas impregnados nas partículas transportadas pela água, o desaparecimento de mananciais, o aumento do aporte de sedimentos pelas bacias hidrográficas, a intensificação dos efeitos das inundações, entre outros impactos ambientais negativos (GUERRA, 2005). No Estado de São Paulo, estima-se que $80 \%$ da área agrícola esteja sofrendo erosão, que provoca a perda de mais de 200 milhões de toneladas de solo por ano, dos quais $70 \%$ chegam aos mananciais na forma de sedimentos (ZOCCAL, 2007). Diante desse cenário, faz-se necessário analisar e quantificar o processo erosivo e o aporte de sedimentos no exutório das bacias hidrográficas por meio de modelos que levem em consideração os fatores que desencadeiam a desagregação do solo, o transporte e a deposição nas vertentes e/ou nos cursos d'água, ou seja, relacionados às chuvas, ao solo, ao relevo, à cobertura vegetal, ao manejo agrícola e à estrutura hidrológica e da paisagem, para que se possa simular o efeito de possíveis usos da terra e manejos do solo no controle desses processos.

O WaTEM/SEDEM (Water and Tillage Erosion Model / Sediment Delivery Model, ou Modelo de Erosão Hídrica e por Preparo do Solo / Modelo de Aporte de Sedimentos) é um modelo espacialmente distribuído desenvolvido pelo Grupo de Pesquisa em Geografia Física e Regional da Universidade Católica de Leuven (KU Leuven), na Bélgica (VAN OOST; GOVERS; DESMET, 2000; VAN ROMPAEY et al., 2001), capaz de predizer as taxas anuais de perda de solo e deposição de sedimentos por erosão hídrica, além do aporte de sedimentos na saída da bacia hidrográfica, a partir de valores médios anuais dos parâmetros de entrada (VERSTRAETEN et al., 2002).

O modelo é estruturado em três componentes: avaliação da taxa de erosão média anual, da capacidade média anual de transporte de sedimentos dos pixels e algoritmo de roteamento de sedimentos, que redistribui os sedimentos produzidos sobre a bacia hidrográfica levando em consideração sua topologia e o padrão espacial da capacidade de transporte (VAN ROMPAEY et al., 2001). O componente de erosão consiste em uma versão adaptada da Equação Universal de Perda de Solo Revisada (RUSLE) (RENARD et al., 1997), dada pela Equação 1:

$E=R{ }^{*} K{ }^{*} L{ }^{*} S * C * P$

Em que: $E$ é a perda de solo média anual $\left(\mathrm{kg} \cdot \mathrm{m}^{-2} \cdot \mathrm{ano}^{-1}\right)$; R é o fator erosividade da chuva (MJ.mm.m $\left.{ }^{2} \cdot \mathrm{h}^{-1} \cdot \mathrm{ano}^{-1}\right) ; \mathrm{K}$ é a erodibilidade do solo $\left(\mathrm{kg} \cdot \mathrm{h} \cdot \mathrm{MJ}^{-1} \cdot \mathrm{mm}^{-1}\right) ; \mathrm{L}$ é o comprimento da encosta; $\mathrm{S}$ é a declividade do terreno; $\mathrm{C}$ o fator de uso da terra e manejo das culturas; e $\mathrm{P}$ o fator de práticas de controle da erosão.

A capacidade de transporte de sedimentos média anual (TC), que corresponde à máxima massa de solo que pode sair do pixel por unidade de comprimento do pixel $\left(\mathrm{kg} \cdot \mathrm{m}^{-1}\right)$, é dada pela Equação 2:

$\mathrm{TC}=\mathrm{K}_{\mathrm{TC}}{ }^{*} \mathrm{E}_{\mathrm{PR}}$

Em que: KTc corresponde ao coeficiente de capacidade de transporte $(m)$ e EPR é o potencial de erosão em sulcos $\left(\mathrm{kg} \cdot \mathrm{m}^{-2} \cdot\right.$ ano $\left.^{-1}\right)$.

Considerando que $E_{P R}$ resulta da diferença entre o potencial de erosão total (produto entre os fatores $\mathrm{R}, \mathrm{K}, \mathrm{L}$ e S) e o potencial de erosão entressulcos, a combinação das equações dá origem à Equação 3 (SHI et al., 2012; DIDONÉ; MINELLA; EVRARD, 2017):

$T C=K_{T C}{ }^{*} R * K^{*}\left(L S-4,12 * S_{E S}^{0,8}\right)$

Em que $S_{E S}$ é o gradiente de declive entressulcos $\left(\mathrm{m} \cdot \mathrm{m}^{-1}\right)$.

Os valores de $\mathrm{K}_{\mathrm{TC}}$ dos diversos usos e manejos do solo são determinados por meio de calibração. 
A transferência dos sedimentos erodidos da fonte para a rede de drenagem é realizada por um algoritmo de fluxo múltiplo, que determina o caminho do fluxo na vertente. Para cada pixel, os sedimentos recebidos dos pixels a montante são somados à quantidade de sedimentos produzida nele. Se o total de sedimentos for inferior à capacidade de transporte, todo o sedimento é transferido para jusante. Se a soma excede a capacidade de transporte, a saída de sedimentos do pixel é limitada a esta capacidade, o que reduz a taxa de erosão, e se TC for inferior à entrada de sedimentos, haverá deposição de sedimentos no pixel (VAN ROMPAEY et al., 2001). Ao atingir o rio, o sedimento é direcionado ao exutório da bacia, já que o modelo não leva em consideração a erosão/deposição no canal de drenagem nem em suas margens (KEESSTRA et al., 2009). O WaTEM/SEDEM produz um mapa representando a quantidade de erosão ou de deposição de sedimentos em cada pixel e calcula a quantidade de sedimentos que atinge a rede de drenagem e é exportada da bacia.

Por ser um modelo espacialmente distribuído de escala temporal anual utilizado na predição dos processos de erosão, deposição e aporte de sedimentos, o modelo WaTEM/SEDEM agregou parâmetros de um modelo físico baseado em eventos, como a capacidade de transporte de sedimentos, a um modelo empírico de escala temporal anual, a RUSLE, que estima as perdas anuais de solo por erosão (VAN ROMPAEY et al., 2005).

O modelo WaTEM/SEDEM foi calibrado e aplicado com relativo sucesso em bacias hidrográficas de diversas regiões do planeta e de diferentes tamanhos, climas e condições de uso da terra, para a simulação dos processos erosivos, de deposição e de aporte de sedimentos nos exutórios em escala anual. Além da pesquisa em bacias hidrográficas da Bélgica para desenvolvimento e calibração do modelo, foi utilizado por Jordan et al. (2005), que realizaram uma análise histórica da produção de sedimentos na bacia Kali, área de contribuição do Lago Balaton, na Hungria; por Van Rompaey; Krasa; Dostal (2007), na bacia de drenagem Orlice, República Tcheca, durante a coletivização das propriedades agrícolas conduzida pelo regime comunista e após esse período; e por Keesstra et al. (2009), que avaliaram a dinâmica dos processos erosivos nas sub-bacias dos rios Rokava e Dragonja superior, pertencentes à bacia do Rio Dragonja, sudoeste da Eslovênia, decorrente das mudanças socioeconômicas ocorridas no país após a Segunda Guerra Mundial, caracterizadas pela redução populacional, abandono de campos agrícolas e pelo reflorestamento natural de áreas consideráveis das sub-bacias.

Alatorre; Beguería; García-Ruiz (2010) calibraram o WaTEM/SEDEM em bacia hidrográfica grande $\left(1.504 \mathrm{~km}^{2}\right)$ e de elevada amplitude altimétrica $(2.954 \mathrm{~m})$, a bacia do reservatório Barasona, drenada pelos Rios Ésera e Isábena nos Pirineus Centrais da Espanha. Shi et al. (2012) verificaram que as mudanças nas práticas de manejo dos cultivos e do solo na bacia do Rio Wangjiaqiao, nas proximidades da Usina de Três Gargantas, China, foram mais eficientes na redução do aporte de sedimentos que as medidas de controle de sedimentos simuladas, tais como lagoas de retenção de água e de sedimentos. Haregeweyn et al. (2013) estudaram doze bacias de reservatórios na região de Tigray, norte da Etiópia, compararam duas versões do algoritmo de capacidade de transporte de sedimentos do modelo WaTEM/SEDEM, o expresso na equação 3 e o apropriado para bacias com erosão em voçorocas, e demonstraram que eles não apresentam diferença estatística significativa entre si.

No Brasil, a única aplicação do modelo WaTEM/SEDEM foi realizada por Didoné; Minella; Evrard (2017) na bacia do Rio Conceição, Rio Grande do Sul, bacia amplamente dominada por cultivos agrícolas sob plantio direto. Os cenários simulados evidenciaram que o sistema de plantio direto por si só não foi eficaz na redução da erosão e do aporte de sedimentos na saída da bacia, mas que conjugado a práticas conservacionistas como o plantio em nível, terraceamento e manutenção das Áreas de Preservação Permanente (APP) cobertas com vegetação, reduziu o aporte de sedimentos no exutório da bacia em até $541 \%$. Tal pesquisa, porém, foi realizada na escala anual e o modelo foi calibrado por dados de quatro anos de monitoramento climático, hidrológico e sedimentométrico.

Diante da falta dos referidos dados medidos em longo prazo na área de estudo deste trabalho, e do fato de que as maiores taxas de erosão e de aporte de sedimentos no decorrer do ano ocorrem em poucos eventos de chuvas intensas, buscou-se adaptar o modelo WaTEM/SEDEM para a simulação do processo erosivo na escala de evento individual de chuva. A opção pelo seu uso em detrimento de 
outros modelos mais robustos como o EROSION-3D, o openLISEM e o SWAT, se deu pela sua simplicidade e pela possibilidade de determinar e/ou mapear todos os seus parâmetros de entrada e os necessários à sua calibração. Considerando o efeito da vegetação arbórea na retenção de sedimentos, sobretudo as localizadas nas faixas marginais aos cursos d'água, este trabalho também simulou a produção e o aporte de sedimentos na condição de adequação do uso da terra da bacia hidrográfica à legislação florestal brasileira (BRASIL, 2012).

Nesse contexto, os objetivos deste trabalho foram calibrar o modelo WaTEM/SEDEM para simular os processos de erosão, deposição e aporte de sedimentos no exutório das bacias hidrográficas em eventos individuais de chuvas; e simular os referidos processos na bacia do Ribeirão São Domingos, Santa Cruz do Rio Pardo - SP, em duas condições de uso da terra: uso atual (ano 2018) e adequação à legislação florestal brasileira (cenário LF).

\section{MATERIAL E MÉTODOS}

\section{Área de estudo}

A bacia hidrográfica do Ribeirão São Domingos está localizada na porção central do município de Santa Cruz do Rio Pardo, no centro-oeste do Estado de São Paulo (Figura 1). É limitada pelas

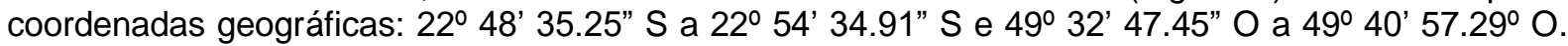
Possui área de 78,77 km² e altitudes mínima e máxima de 454 e 658 metros, com declividade média de $6,85 \%$.

Figura 1 - Bacia hidrográfica do Ribeirão São Domingos: localização.

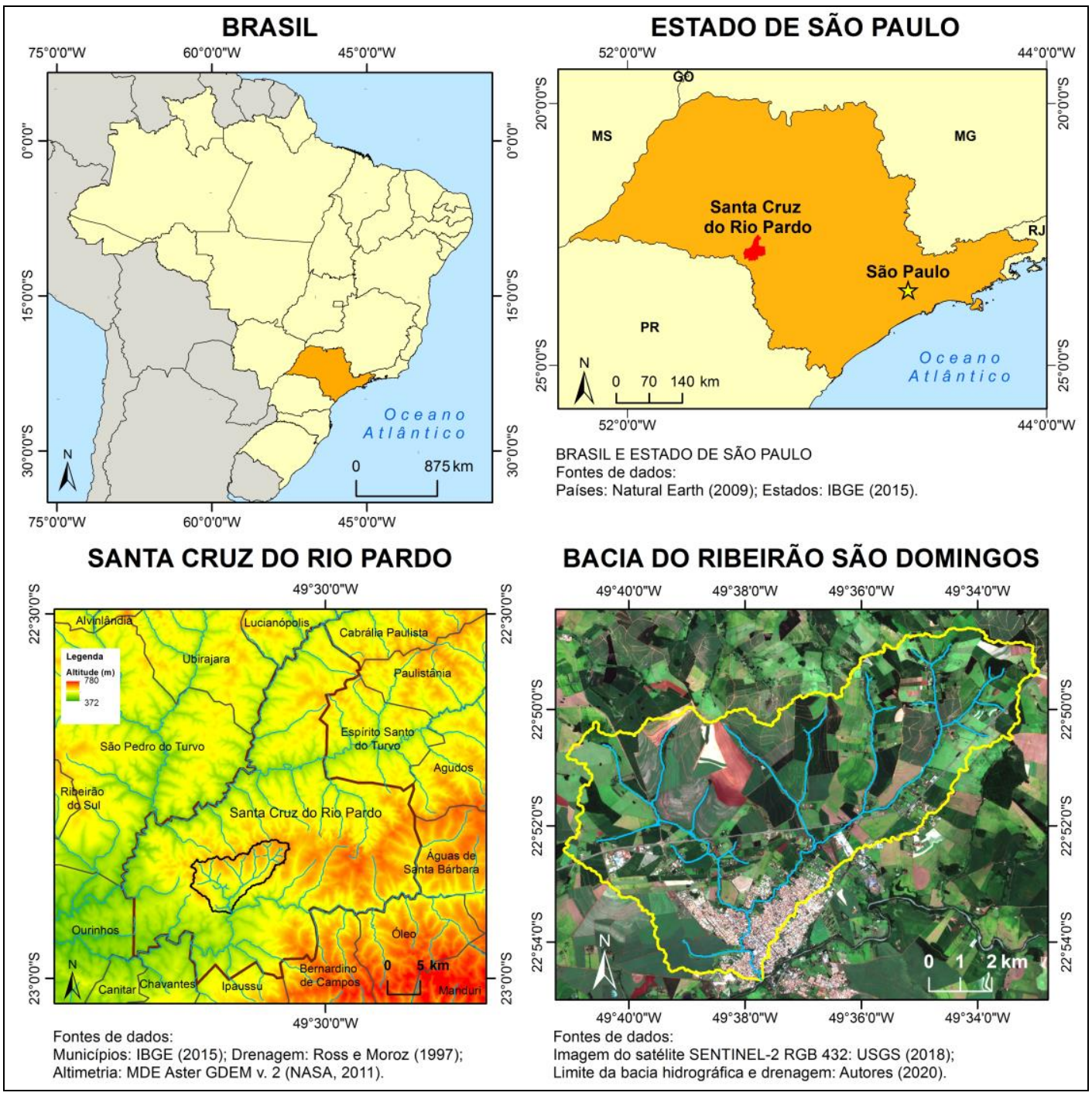

Organização - dos Autores (2020). 
A área de estudo encontra-se na Bacia Sedimentar do Paraná, unidade geotectônica estabelecida na Plataforma Sul-Americana a partir do período Devoniano inferior, senão do Siluriano, na Era Paleozóica, caracterizada pelo acúmulo de grandes espessuras de sedimentos, lavas basálticas e sills de diabásio (IPT, 1981). As formações geológicas predominantes, estabelecidas na Era Mesozóica, são: Serra Geral, do Grupo São Bento, representada pelos basaltos de textura afanítica intercalados por arenitos intertrapeanos (IPT, 1981), sobre a qual se localizam a zona urbana do município e o médio curso dos rios principais; a Formação Adamantina, do Grupo Bauru, caracterizada pelos arenitos de granulação fina a muito fina, coincidentes com as cabeceiras de drenagem e divisores de água nas porções oeste, norte e leste da bacia; e a Formação Marília, do mesmo grupo, em uma pequena mancha em seu limite nordeste, representada pelos arenitos grosseiros com nódulos e cimentação carbonática (SOARES et al., 1980).

Em relação aos aspectos geomorfológicos, a bacia em estudo localiza-se na unidade morfoescultural Planalto Ocidental Paulista e na unidade geomorfológica Planalto Centro-Ocidental, caracterizada por formas de relevo denudacionais constituídas de colinas amplas e baixas com topos convexos ou aplanados e tabulares, altitudes entre 400 e $700 \mathrm{~m}$ e declividade entre 2 e $10 \%$ (ROSS e MOROZ, 1997). O grau de entalhamento dos vales fraco a muito fraco, as declividades baixas e as dimensões interfluviais grandes a muito grandes favorecem a mecanização agrícola e a infiltração da água da chuva, em detrimento do escoamento superficial.

O clima de Santa Cruz do Rio Pardo, classificado a partir das normais climáticas apresentadas por Miranda et al. (2005) e dos critérios estabelecidos por Rolim et al. (2007) para a classificação de Köppen-Geiger, é do tipo Am, tropical chuvoso com inverno seco, com precipitação inferior a $60 \mathrm{~mm}$ no mês mais seco (agosto), temperatura média do mês mais frio (julho) de $18^{\circ} \mathrm{C}$ e dos meses mais quentes (janeiro e dezembro) de $26^{\circ} \mathrm{C}$. O índice pluviométrico médio anual é de $1.475,3 \mathrm{~mm}$, concentrado nos meses de outubro a março.

A vegetação original da área de estudo é a Floresta estacional semidecidual, subtipo "Vegetação secundária e atividades agrárias" (IBGE, 2004). Restam atualmente 665,4 ha de vegetação arbórea na referida área, composta também de espécies exóticas. Quanto à hidrografia, os principais ribeirões da área de estudo são o São Domingos e o Mandaçaia, que se confluem no perímetro urbano de Santa Cruz do Rio Pardo para formar um rio de 4⿳亠丷厂 ordem até desaguar no Rio Pardo. A bacia está inserida na Unidade de Gerenciamento de Recursos Hídricos do Médio Paranapanema - UGRHI-17 (SÃO PAULO, 1996). Os tipos de solo existentes refletem as formações geológicas locais, além dos demais fatores de formação, e apresentam diferentes graus de suscetibilidade à erosão. A área de estudo é composta de Latossolos (59,17\%), Nitossolos (26,64 \%), Argissolos (10,33\%) e Gleissolos (3,86 \%) (DEMARCHI, 2019).

\section{PROCEDIMENTOS METODOLÓGICOS}

Os procedimentos necessários à realização da modelagem de erosão com o WaTEM/SEDEM podem ser divididos em: determinação e mapeamento das variáveis da RUSLE e da estrutura da paisagem, medições de vazão e de concentração de sedimentos em suspensão (CSS), calibração do modelo e simulações de erosão nas diferentes condições de uso da terra.

A variável da RUSLE erosividade da chuva (fator R) foi obtida por meio do índice de energia e intensidade $\mathrm{El}_{30}$, que representa o produto da energia cinética total da chuva (MJ.ha-1) pela sua intensidade máxima $\left(\mathrm{mm} . \mathrm{h}^{-1}\right)$ em um período contínuo de 30 minutos (WISCHMEIER, 1959). Os dados pluviométricos utilizados no cálculo de $\mathrm{El}_{30}$ foram medidos por um pluviógrafo automático de caçamba basculante marca Davis, com área de captação de $346 \mathrm{~cm}^{2}$, precisão de $0,254 \mathrm{~mm}$ e intervalo de registro de dados definido em 5 minutos, instalado nas proximidades das coordenadas centrais da área de estudo.

A energia cinética $(E)$ de cada segmento de chuva foi calculada em função da intensidade da chuva pela equação proposta por Wischmeier e Smith (1958) e convertida ao Sistema Internacional de Unidades por Foster et al. (1981). Como o intervalo de medida foi de 5 minutos, a intensidade (mm.h 1) foi obtida pela multiplicação de cada registro pluviométrico por 60 minutos, seguida da divisão por 5 minutos. Para intensidades superiores a $76 \mathrm{~mm} \cdot \mathrm{h}^{-1}$, adotou-se $\mathrm{E}=0,283 \mathrm{MJ} \cdot \mathrm{ha}^{-1} \cdot \mathrm{mm}^{-1}$ (WISCHMEIER e SMITH, 1958). Ao multiplicar o índice pluviométrico total medido nos 30 minutos de maior intensidade por dois, obteve-se o índice $\mathrm{l}_{30}\left(\mathrm{~mm} . \mathrm{h}^{-1}\right)$.

A erodibilidade do solo (fator $\mathrm{K}$ ) foi determinada pela equação empírica concebida por Denardin (1990) a partir de atributos químicos e físicos dos horizontes superficiais e subsuperficiais dos 75 
pontos de amostragem utilizados no levantamento semidetalhado de solos da área de estudo executado por Demarchi (2019), de acordo com os critérios do Sistema Brasileiro de Classificação de Solos (EMBRAPA, 2013).

Na equação de Denardin (1990), as variáveis M e DMP (diâmetro médio ponderado) são calculadas a partir das frações granulométricas areia grossa, areia fina, silte e argila; a variável P é a classe de permeabilidade do solo, definida por Wischmeier; Johnson; Cross (1971) a partir da textura do perfil; e a variável $\mathrm{R}$ é definida pelo produto da fração areia (exceto a classe areia muito fina) e do teor de matéria orgânica, dividido por 100 . Os valores de erodibilidade dos horizontes superficiais e subsuperficiais foram ponderados pela espessura de cada horizonte e em seguida somados. Adotouse a espessura média de 0,2 $\mathrm{m}$ para os horizontes superficiais, característica dos horizontes $\mathrm{A}$ moderados, e de 0,8 m para os horizontes subsuperficiais, totalizando 1 metro de profundidade. Para os Gleissolos, consideraram-se as espessuras médias de $0,45 \mathrm{~m}$ e $0,55 \mathrm{~m}$, respectivamente, observadas em campo nos horizontes superficiais e subsuperficiais. O mapa do fator $\mathrm{K}$ seguiu os limites das unidades de mapeamento do mapa de solos e as características do relevo.

O fator topográfico (LS) da RUSLE, que representa as variáveis comprimento de rampa (L) e declividade (S), foi calculado pelo modelo WaTEM/SEDEM a partir do modelo digital de elevação (MDE) Aster GDEM-2 (NASA, 2011), convertido em arquivo vetorial de pontos, reamostrado para a resolução espacial de 20 metros pela ferramenta Topo to raster do SIG ArcGIS 10.3.1, com licença de uso para o Laboratório de Geoprocessamento da UNESP - Câmpus de Ourinhos, e suavizado por um filtro de média com janela móvel de $7 \times 7$ para eliminação das depressões e rugosidades. $O$ mapa do fator LS foi gerado pelo modelo por meio do algoritmo de Desmet e Govers (1996) para o cálculo do fator L. Para a determinação do fator S, utilizou-se o algoritmo de Govers (1991), recomendado para bacias hidrográficas com presença de erosão em sulcos. O expoente "m" do fator L, também definido por Govers (1991), foi de 0,755.

Os mapas do fator C (uso e manejo do solo) derivaram dos mapas de uso da terra do ano 2018 e de adequação à legislação florestal brasileira. Os valores $\mathrm{C}$ utilizados nos mapas foram extraídos da literatura (Tabela 1).

Tabela 1 - Fator C dos usos e manejos do solo encontrados na área de estudo.

\begin{tabular}{|c|c|c|}
\hline Uso e manejo do solo & Fator C & Referência \\
\hline $\begin{array}{l}\text { Zona urbana, Expansão urbana, Área industrial e } \\
\text { Sedes rurais e chácaras }\end{array}$ & 0,03 & Lopes et al. (2007) \\
\hline Solo exposto e Estrada de terra & 1,0 & Wischmeier e Smith (1978) \\
\hline Rodovia & 0 & - \\
\hline Café com espaçamento de $3 \times 2 \mathrm{~m}$ & 0,1004 & Prochnow et al. (2005) \\
\hline Fruticultura e Urucum & 0,135 & Silva et al. (2010) \\
\hline $\begin{array}{l}\text { Cana-de-açúcar com 1ํo corte um ano após o } \\
\text { plantio }\end{array}$ & 0,1076 & Cavalieri (1998) \\
\hline Mandioca com plantio convencional ( $1^{\circ}$ ano) & 0,5 & Roose (1976) \\
\hline $\begin{array}{l}\text { Milho em Sistema de Plantio Direto e sucessão } \\
\text { com várias culturas }\end{array}$ & 0,061 & Bertol; Schick; Batistela (2002) \\
\hline $\begin{array}{l}\text { Soja e trigo em sucessão e Sistema de Plantio } \\
\text { Direto }\end{array}$ & 0,1043 & Bertol; Schick; Batistela (2001) \\
\hline Horticultura & 0,15 & $\begin{array}{c}\text { Marques; Lombardi Neto; Bacellar } \\
\text { (2003) }\end{array}$ \\
\hline Pastagem degradada & 0,061 & Galdino (2012) \\
\hline Pastagem conservada & 0,007 & Galdino (2012) \\
\hline Eucalipto com corte a cada 7 anos & 0,047 & Silva et al. (2010) \\
\hline Vegetação arbórea e Vegetação de áreas úmidas & 0,001 & Gonçalves (2002) \\
\hline Campestre & 0,0053 & Demarchi (2019) \\
\hline
\end{tabular}

Organização - dos Autores (2019).

O mapa de uso da terra de 2018 foi elaborado por análise visual e vetorização manual sobre as imagens dos satélites Worldview-2 (16/07/2017) da DigitalGlobe (2017b) e GeoEye-1 (11/12/2017) da DigitalGlobe (2017a), disponíveis no aplicativo gratuito Google Earth Pro, sendo os usos da terra atualizados pela análise de composições coloridas de imagens dos satélites Landsat-8, sensor OLI, tomadas em 10/09/2017, 01/02/2018 e 17/02/2018 (INPE, 2017; 2018c); Resourcesat-2, sensor LISS III, tomadas em 12/03/2018 e 23/05/2018 (INPE, 2018d); e CBERS-4, sensores MUX (21/01/2018 e 
14/03/2018) e PAN (16/02/2018 e 12/09/2018) (INPE, 2018a,b). O mapa correspondeu ao mês de janeiro de 2018 por representar o período chuvoso e de maior erosividade da chuva, mas as imagens dos demais meses auxiliaram na identificação do uso da terra a partir do calendário agrícola.

No mapa de adequação do uso da terra à legislação florestal brasileira, representada pela Lei no 12.651/2012 (BRASIL, 2012) e alterações, foram delimitadas APP e atribuídos o uso "vegetação arbórea" à largura de 30 metros nas faixas marginais dos cursos d'água, ao raio de 50 metros no entorno das nascentes, e à largura de 50 metros nas faixas marginais aos reservatórios d'água artificiais de área superior a 1 ha. As Reservas Legais $(R L)$ foram alocadas nos imóveis rurais com área superior a 80 ha, equivalente a 4 módulos fiscais estabelecidos pelo INCRA para o município, contabilizando os fragmentos de vegetação arbórea já existentes e as APP. As áreas faltantes para totalizar $20 \%$ das propriedades rurais foram alocadas nas áreas adjacentes às APP e aos fragmentos florestais existentes e, por último, nas áreas planas dos divisores de água e interflúvios, para favorecer a recarga dos aquíferos. Os limites das propriedades rurais foram extraídos do banco de dados do Sistema do Cadastro Ambiental Rural (SICAR) (BRASIL, 2018). Nos imóveis com área inferior a 80 ha, foram fixadas como RL as áreas ocupadas por vegetação arbórea no ano 2018, conforme previsto na Lei $n^{\circ} 12.651 / 2012$. As áreas mapeadas como "vegetação de áreas úmidas" e "pastagem degradada" no ano 2018 foram convertidas para "vegetação arbórea" e "pastagem conservada", denotando o uso conservacionista do solo no mapa de adequação à legislação florestal.

$O$ fator práticas conservacionistas $(P)$ não é utilizado no modelo WaTEM/SEDEM, mas o efeito do terraceamento e do plantio em nível nas áreas agrícolas foi levado em consideração na composição da variável eficiência de retenção de sedimentos das parcelas (ERS), parâmetro relacionado à estrutura da paisagem que representa a contribuição do pixel para a redução da área de contribuição ao escoamento superficial a jusante, influenciado pelo uso e manejo do solo da parcela agrícola à qual pertence (NOTEBAERT et al., 2006). Os valores de ERS utilizados neste trabalho são apresentados na Tabela 2.

Tabela 2 - Eficiência de retenção de sedimentos das parcelas da área de estudo.

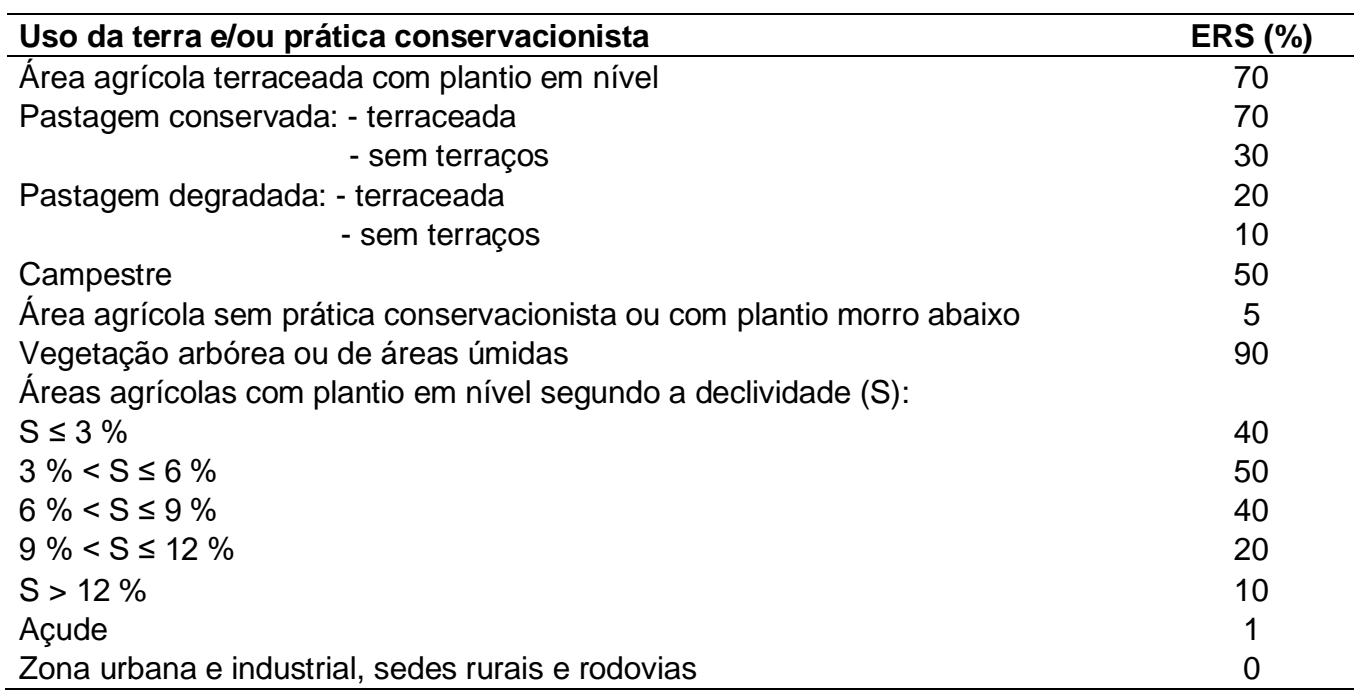

Organização - dos Autores (2019).

Os valores de ERS adotados para as áreas agrícolas cultivadas em nível são equivalentes aos propostos por Donzeli et al. (1992) para o fator P da EUPS, considerando o efeito da declividade na proteção dos solos sob plantio em nível contra a erosão. A ERS de $90 \%$ das áreas florestais foi utilizada por Didoné; Minella; Evrard (2017) na aplicação do modelo WaTEM/SEDEM a uma bacia hidrográfica situada no Rio Grande do Sul. Às áreas agrícolas terraceadas, atribuiu-se o valor de PTEF de $70 \%$, considerando que os terraços reduzem as perdas de solo em 70 a $80 \%$ e de água em até $100 \%$ (PIRES e SOUZA, 2003). As demais combinações de uso da terra e práticas conservacionistas receberam valores de ERS em função da proteção fornecida ao solo, definidos por calibração, tendo como referência as áreas agrícolas terraceadas. A modelagem não considerou a retenção de sedimentos nos açudes devido à inexistência de dados de capacidade de armazenamento de água e de retenção de sedimentos.

$\begin{array}{lllll}\text { Caminhos de Geografia } \quad \text { Uberlândia-MG } & \text { v. 21, n. } 78 \quad \text { Dez/2020 } & \text { p. 117-137 } & \text { Página } 123\end{array}$


A variável conectividade da parcela $(\mathrm{CP})$ diz respeito à redução da área de contribuição para o escoamento a jusante de um pixel localizado na borda das parcelas, na transição de qualquer uso da terra para uso agrícola ou para floresta e pastagem. Neste trabalho, após testes realizados na calibração do modelo WaTEM/SEDEM, estabeleceu-se o valor $10 \%$ para áreas agrícolas e $20 \%$ para florestas e pastagens.

O mapa de parcelas diferenciou e codificou os elementos da estrutura da paisagem da bacia hidrográfica em rodovias e áreas construídas, rios, áreas agrícolas (código $1 \mathrm{a} \mathrm{n}$, sendo $\mathrm{n}$ o número de parcelas agrícolas), florestas e pastagens.

A vazão do Ribeirão São Domingos nos eventos de chuvas intensas foi calculada pelo método do flutuador (PALHARES et al., 2007), dado pela Equação 4:

$Q=(A * L * C) / T$

Em que: $Q$ é a vazão $\left(\mathrm{m}^{3} / \mathrm{s}\right)$; A é a média da área das duas seções transversais molhadas do rio $\left(\mathrm{m}^{2}\right)$; $L$ é a distância entre as seções transversais, padronizada em $6 \mathrm{~m}$; $C$ é o fator de correção, fixado em 0,9 para rios de fundo barrento, e $T$ é o tempo de deslocamento do flutuador no comprimento $L$, dado em segundos.

O nível da água, utilizado na obtenção da área média das seções transversais, foi medido pelo conjunto de sensores automáticos marca Onset, modelos U20L-02 e U20L-04, sendo o primeiro instalado no fundo do rio, próximo ao talvegue em um tubo de PVC perfurado, e o segundo instalado fora dele para realizar a compensação barométrica e corrigir a altura da água medida pelo outro sensor. As medições foram realizadas no intervalo de 5 minutos. Realizou-se também um levantamento topográfico por nivelamento geométrico das duas seções transversais utilizadas na medição da vazão, que possibilitou calcular a área molhada das seções em cada nível da água registrado durante os eventos de chuvas, a partir do programa Auto-CAD Map 2005, licenciado para o Laboratório de Geoprocessamento da UNESP - Câmpus de Ourinhos.

Para o cálculo do tempo $T$, foram realizadas 14 medições de vazão pelo método do flutuador com o rio em diferentes cotas fluviométricas, de modo a ajustar uma curva-chave de tempo de deslocamento em função do nível da água. $O$ ajuste da equação exponencial da curva-chave foi realizado pela ferramenta iterativa "Solver", complemento do programa Microsoft Excel, com o método GRC Não linear, de forma a minimizar a soma dos quadrados dos desvios dos tempos estimado e observado. $\mathrm{Na}$ equação gerada, o tempo de deslocamento do flutuador estimado para as maiores cotas fluviométricas foi muito elevado e provocou a redução da vazão do rio, ao invés de aumentá-la. Para minimizar o erro, plotaram-se em um gráfico os tempos de deslocamento do flutuador em função dos níveis médios da água medidos em campo e ajustou-se uma equação do tipo potencial para determinação de $\mathrm{T}$, com coeficiente de determinação de 0,9876.

As amostragens de água para determinação da CSS foram realizadas a partir de uma ponte localizada $415 \mathrm{~m}$ a montante da foz do Ribeirão São Domingos no Rio Pardo. A cada sete dias, uma amostragem foi realizada para caracterizar a condição de CSS anterior a um possível evento de chuva intensa. Durante os eventos chuvosos, coletaram-se amostras a cada 30 minutos no período de ascensão do hidrograma, e em frequências menores no período de recessão, levando-se em consideração que aproximadamente $90 \%$ do transporte de sedimentos em suspensão ocorre durante o período de cheia (POLETO, 2014), e que o hidrograma atinge o pico na área de estudo aproximadamente 1,5 horas após o início da chuva intensa.

Para a realização da amostragem, utilizou-se o amostrador de água $\mathrm{DH}-48$ com bico de 1/4" e haste para operação a vau. O método empregado foi o de igual incremento de largura (IIL), com a seção transversal dividida em seções verticais igualmente espaçadas e velocidade constante de descida e subida do amostrador. A análise da CSS das amostras foi realizada pelo método da filtração de todo o material coletado, com filtro de fibra de vidro de malha $0,45 \mu \mathrm{m}$ e bomba de vácuo acoplada à unidade de filtração. Os procedimentos de amostragem e determinação de CSS são recomendados por Carvalho et al. (2000).

A produção total de sedimentos dos eventos de chuva foi estimada pelo produto da vazão no exutório da bacia pela CSS durante toda a onda de cheia. A estimativa da CSS a cada 5 minutos foi realizada

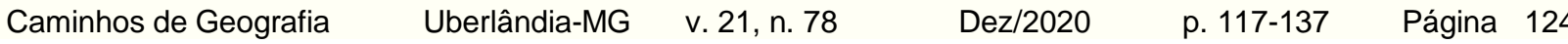


por interpolação linear, a partir dos valores medidos. Admitindo-se um valor de vazão medido por 5 minutos, ele foi transformado de $\mathrm{m}^{3} / \mathrm{s} \mathrm{em} \mathrm{l/s} \mathrm{e} \mathrm{multiplicado} \mathrm{por} 300 \mathrm{~s}$. O volume de água resultante (litros), multiplicado pela CSS (g/l), originou o aporte total de sedimentos $(\mathrm{g})$ dos eventos de chuva.

A calibração do modelo WaTEM/SEDEM consistiu no ajuste dos coeficientes de capacidade de transporte (kTc) dos eventos de chuva reais ocorridos em 20/02, 28/02, 13/03, $25 / 03$ e 20/09/2018, dos quais a vazão e a CSS foram medidas em campo, de forma que o aporte de sedimentos estimado pelo modelo fosse igual ao observado. As variáveis mapeadas para o ano 2018 permaneceram inalteradas, com exceção da erosividade da chuva e do uso e manejo do solo, que corresponderam às datas em que ocorreram.

Os mapas do fator C foram elaborados a partir de imagens NDVI (Índice de Vegetação por Diferença Normalizada, em português) das bandas 4 (vermelho) e 8 (infravermelho próximo) do satélite SENTINEL-2, sensor MSI (Multispectral Instrument), cenas 22/K/FV, de resolução espacial de 10 metros (USGS, 2018). As imagens foram obtidas no nível 1C, ortorretificadas e convertidas em radiância no topo da atmosfera. A correção atmosférica foi realizada no complemento SCP (SemiAutomatic Classification Plugin) do SIG QGIS 2.18.25, software livre e gratuito, pelo método DOS1 (Dark Object Subtraction), resultando nas imagens no nível de processamento 2A.

As imagens NDVI foram convertidas em mapas do fator C da RUSLE pelo método de reescalonamento proposto por Durigon et al. (2014). Como as áreas urbanas consolidadas e em expansão, as áreas industriais, rodovias e os açudes não possuem vegetação, apresentaram valores baixos de NDVI e fator C elevado. Aos primeiros usos da terra, atribuiu-se $C=0,03$ (LOPES et al., 2007), e às rodovias e açudes, $C=0$, por não sofrerem o processo erosivo.

As datas das imagens SENTINEL-2 utilizadas na elaboração dos mapas de fator C foram: 07/02/2018, para chuvas de 20/02 e 28/02/2018; $14 / 03$ (chuva de 13/03/2018); 24/03 (chuva de 25/03/2018) e 22/09 (chuva de 20/09/2018).

$\mathrm{O}$ valor de $\mathrm{C}$ para a variável $\mathrm{kTc}$ limite, que separa as áreas agrícolas (kTc alto) das pastagens e florestas (kTc baixo) foi definido como 0,1. Esse limiar, entretanto, não separou perfeitamente os usos da terra conforme a capacidade de transporte de sedimentos, pois o fator $\mathrm{C}$ derivado do NDVI levou em consideração a densidade da cobertura vegetal ao invés do uso e manejo do solo, constituindo valores distintos dos relacionados na Tabela 1. Inicialmente, os valores testados de kTc baixo e alto seguiram a proporção 1:3,33 entre eles, recomendada por Shi et al. (2012), mas essa proporção foi gradualmente alterada para possibilitar o ajuste correto do modelo.

Definidos os coeficientes kTc baixo e alto ótimos dos eventos de chuva, eles foram analisados aos pares de acordo com a similaridade da faixa de erosividade da chuva, para se determinar os kTc adequados para cada faixa. Os conjuntos de eventos chuvosos foram: 28/02 e 13/03/2018 ( $R=61,68$ e 61,04 MJ.mm.ha- ${ }^{-1} \cdot h^{-1}$, respectivamente); 20/02 e 20/09/2018 ( $R=119,12$ e 107,63 MJ.mm.ha ${ }^{-1} \cdot h^{-1}$, respectivamente). Como a erosividade da chuva do evento ocorrido em 25/03/2018, de 324,88 MJ.mm.ha $a^{-1} \cdot h^{-1}$, não foi encontrada em outro episódio de chuva, os coeficientes $\mathrm{kTc}$ calibrados para o referido evento foram repetidos na validação do modelo.

Para a determinação do coeficiente $\mathrm{kTc}$ baixo ótimo de cada faixa de erosividade, fixou-se o valor de $\mathrm{kTc}$ alto ótimo de cada evento de chuva e realizou-se a simulação de erosão variando o $\mathrm{kTc}$ baixo em intervalos de 0,5 metro. O procedimento inverso foi adotado para encontrar o $\mathrm{kTc}$ alto ótimo. Os coeficientes kTc baixo e alto dos pares de eventos de chuva foram determinados pelo coeficiente de eficiência de Nash-Suttclife (NSE) e pela relação entre erro médio quadrático e desvio padrão das observações (RSR), descritos por Moriasi et al. (2007), cujas variáveis são os valores de aporte de sedimentos predito, observado e médio dos dois eventos de chuva. O coeficiente NSE varia de $-\propto$ a 1 , e o coeficiente RSR, de 0 a 1 . Quanto mais próximo de 1 e de 0 , respectivamente, forem os coeficientes NSE e RSR, mais eficiente será a simulação e melhor será o desempenho do modelo. As combinações de kTc baixo e alto que tiveram maior NSE e menor RSR de cada faixa de erosividade da chuva foram utilizadas na validação do modelo, para simular os processos erosivos e o aporte de sedimentos nas condições de uso da terra de 2018 e do cenário LF. Como se utilizaram os valores do fator $\mathrm{C}$ da Tabela 1, adotou-se kTc limite $=0,05$ para diferenciar os usos e manejos do solo conforme o volume de escoamento superficial que produzem e a capacidade de transporte de sedimentos resultante. 


\section{RESULTADOS E DISCUSSÃO}

A desagregação, o transporte e a deposição de sedimentos, que caracterizam o processo erosivo, resultam da interação entre as características da chuva, a erodibilidade do solo, a configuração do relevo, o uso e cobertura da terra, o manejo agrícola, as práticas de conservação e a estrutura da paisagem.

A Figura 2 apresenta os mapas semidetalhado de solos e de erodibilidade do solo da área de estudo.

Figura 2 - Bacia hidrográfica do Ribeirão São Domingos: a) Mapa semidetalhado de solos; b) Mapa de erodibilidade do solo (t.h.MJ-1 $\cdot \mathrm{mm}^{-1}$ ).

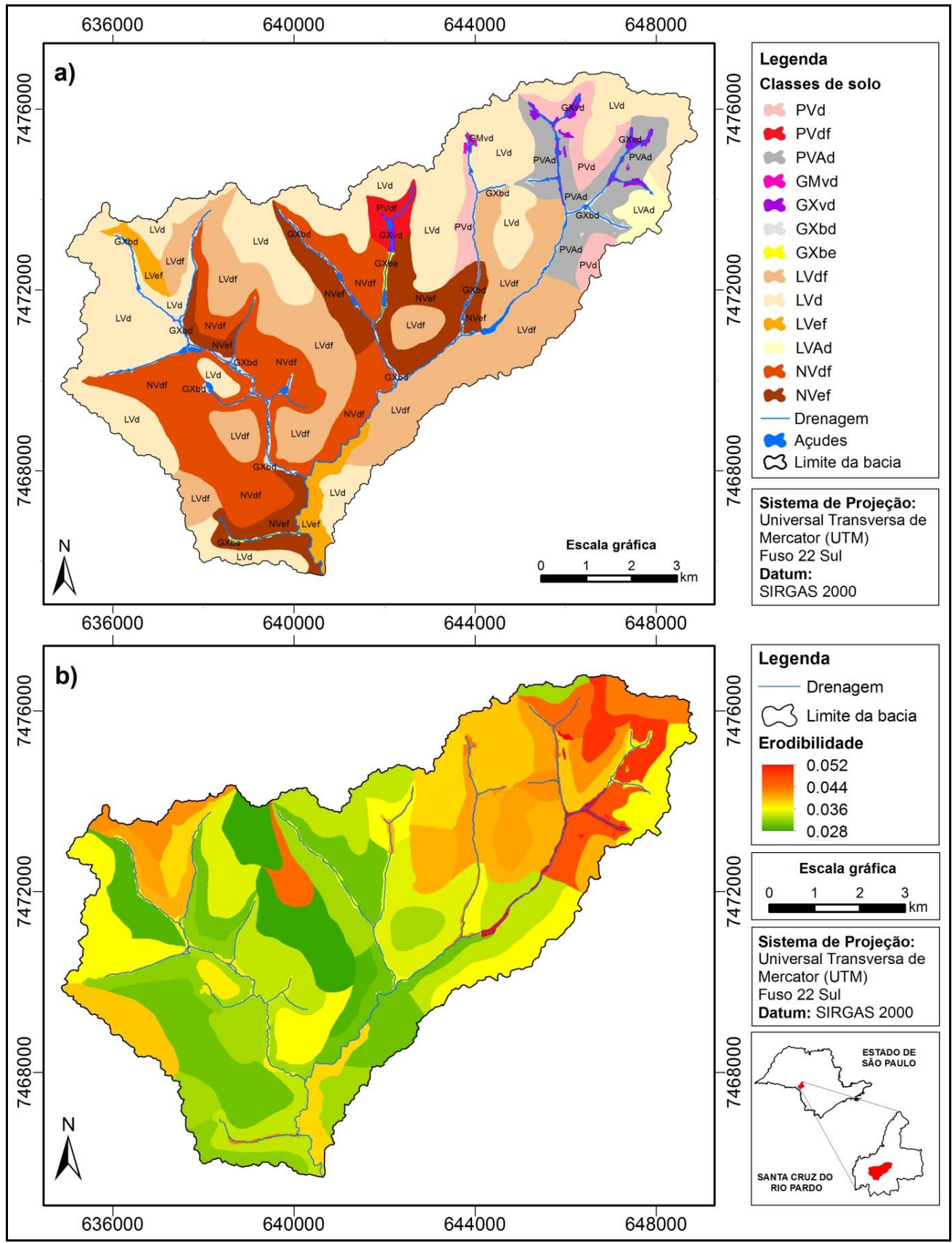

Organização - dos Autores (2019).

Como a erodibilidade foi estimada pela equação de Denardin (1990), a textura do solo foi o principal fator responsável pelas diferenças de suscetibilidade à erosão. Em geral, solos de textura argilosa e muito argilosa, como os Nitossolos, os Latossolos Vermelhos Distroférricos, parte dos Latossolos Vermelhos Distróficos e Eutroférricos e mesmo os Argissolos Vermelhos Distroférricos, oriundos as 
rochas basálticas da Formação Serra Geral, apresentaram índices menores de erodibilidade mesmo tendo menor permeabilidade no perfil decorrente da menor macroporosidade, enquanto as demais classes de Argissolos e os Latossolos de textura arenosa e média, desenvolvidos sobre os arenitos das Formações Adamantina e Marília, apresentaram índices mais elevados de erodibilidade. Os solos sem mudança textural no perfil apresentaram índices médios de erodibilidade, com valores médios entre 0,038 e 0,039 t.h. $\mathrm{MJ}^{-1} \cdot \mathrm{mm}^{-1}$, com exceção dos solos de textura muito argilosa, cujo índice médio foi de 0,032 t.h.MJ ${ }^{-1} \cdot \mathrm{mm}^{-1}$. Para aplicação no modelo WaTEM/SEDEM, os valores de erodibilidade do solo foram convertidos em kg.h. $\mathrm{MJ}^{-1} \cdot \mathrm{mm}^{-1}$.

Os mapas de uso da terra do período chuvoso de 2018 e de adequação à legislação florestal brasileira são apresentados na Figura 3.

Figura 3 - Mapas de uso da terra: a) ano 2018; b) adequação à legislação florestal brasileira.

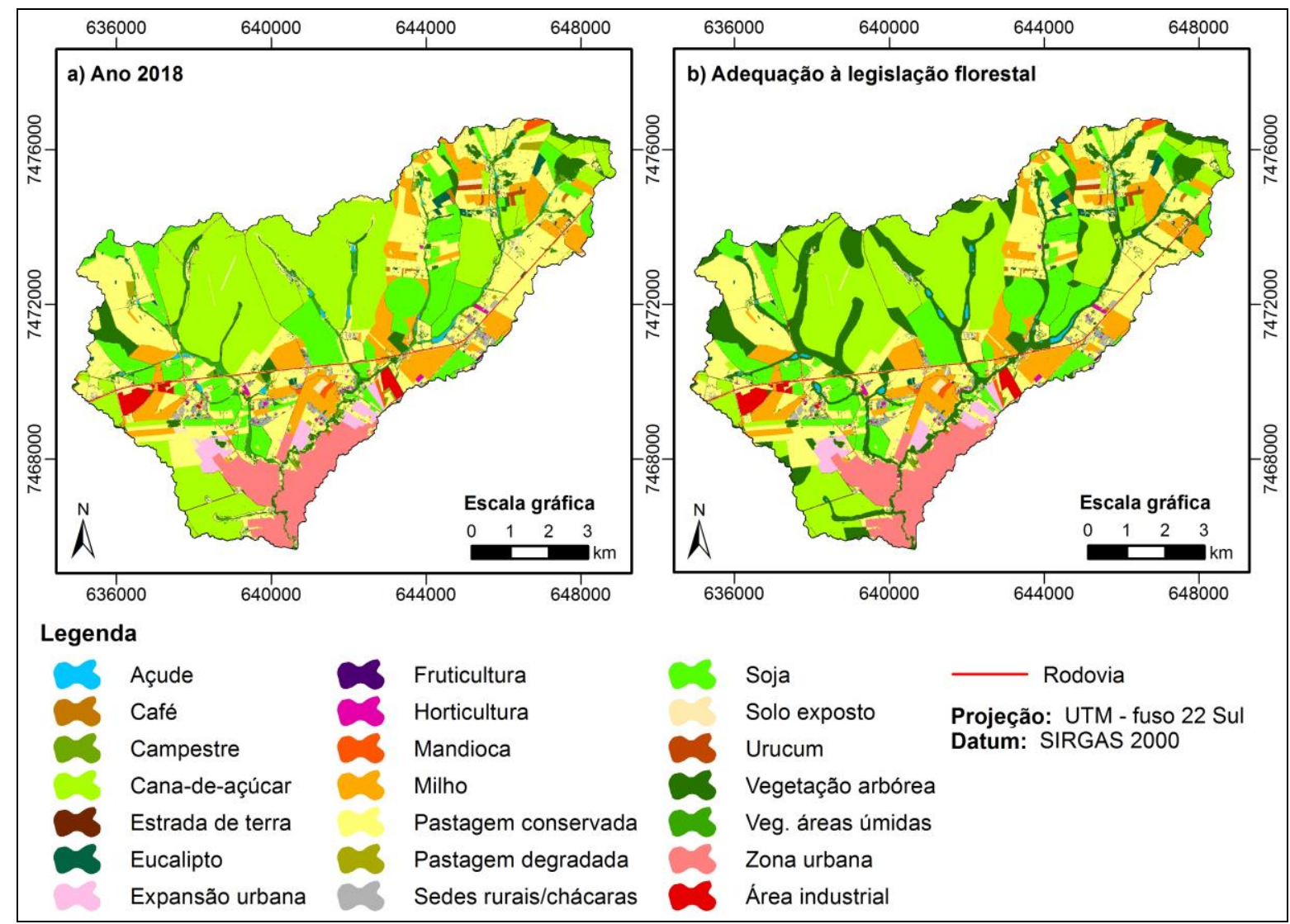

Organização - dos Autores (2019).

No ano 2018, os principais usos identificados na área de estudo foram a cana-de-açúcar $(28,87 \%)$, as pastagens conservadas (24,95\%), a soja (12,89\%), o milho (9,77\%), a vegetação arbórea e de áreas úmidas $(8,45 \%)$ e a zona urbana consolidada e em expansão $(7,38 \%)$. No cenário LF, a vegetação arbórea, incluindo a existente nas APP e RL e a vegetação de áreas úmidas, passou a ocupar $15,55 \%$ da área da bacia hidrográfica em substituição a vários usos, em especial a cana-deaçúcar, o milho e as pastagens.

Os coeficientes de capacidade de transporte de sedimentos são definidos no modelo WaTEM/SEDEM a partir do fator C da RUSLE, em função do uso e manejo do solo. Com o kTc limite estabelecido em 0,05 , as áreas de kTc baixo correspondentes às florestas, pastagens e áreas urbanas representaram $44,86 \%$ e as áreas agrícolas de kTc alto equivaleram a 55,14\% da área de estudo em 2018. No cenário LF, os coeficientes kTc baixo e alto representaram 50,77 \% e 49,23 \% da bacia hidrográfica, respectivamente, o que implica em redução das perdas de solo e da capacidade de transporte, e no aumento da deposição de sedimentos nas APP e RL devido ao aumento de sua área e à localização preferencial nos fundos de vale, em áreas planas.

As Figuras 4 e 5 apresentam, respectivamente, os mapas de práticas conservacionistas e de eficiência de retenção de sedimentos das parcelas das áreas agrícolas do ano 2018 e do cenário LF. 
Figura 4 - Mapas de práticas conservacionistas: a) Ano 2018; b) Adequação do uso e manejo à legislação florestal.

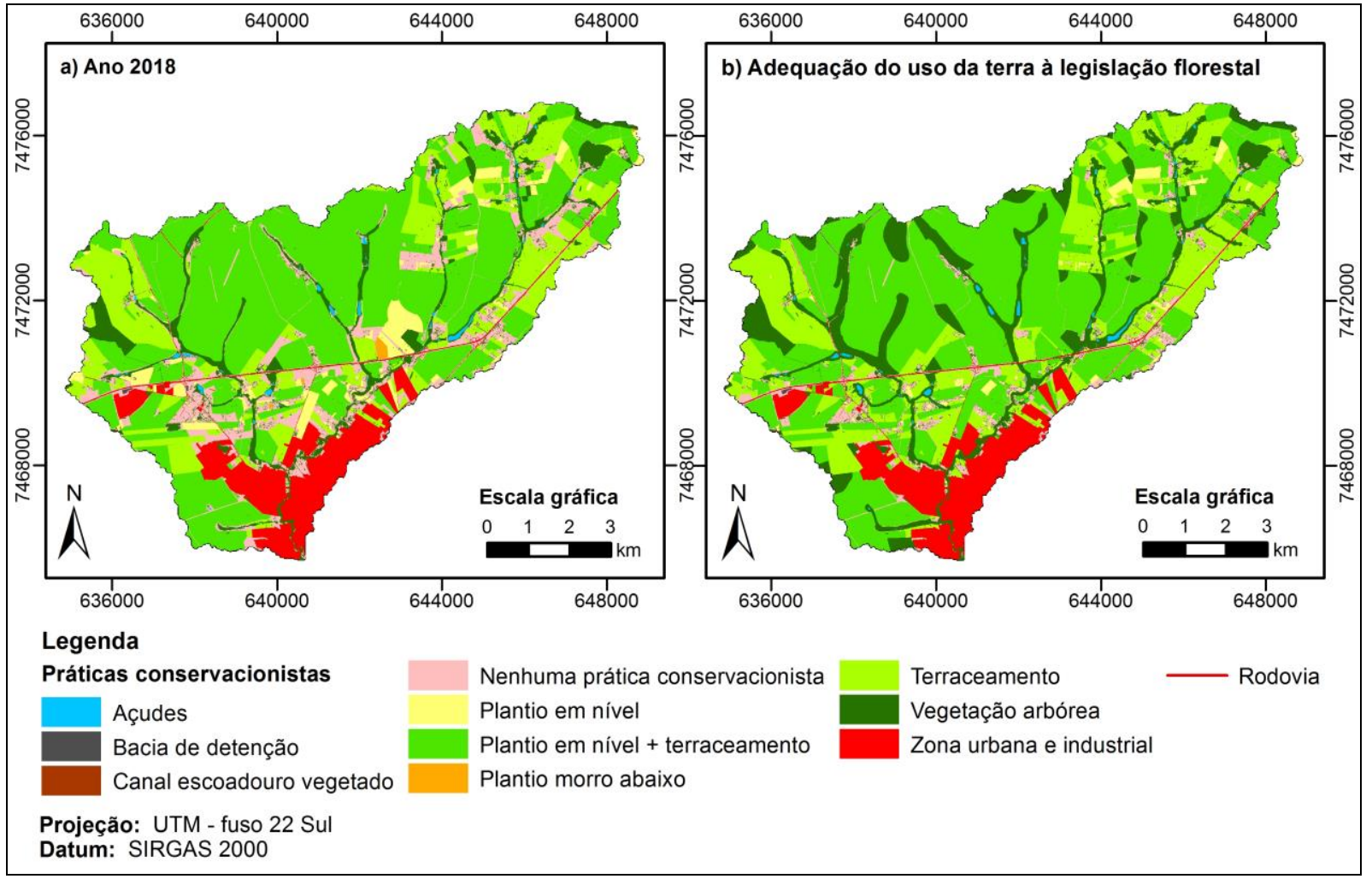

Organização - dos Autores (2019).

Figura 5 - Mapas de eficiência de retenção de sedimentos das parcelas: a) Ano 2018; b) Adequação do uso e manejo à legislação florestal.

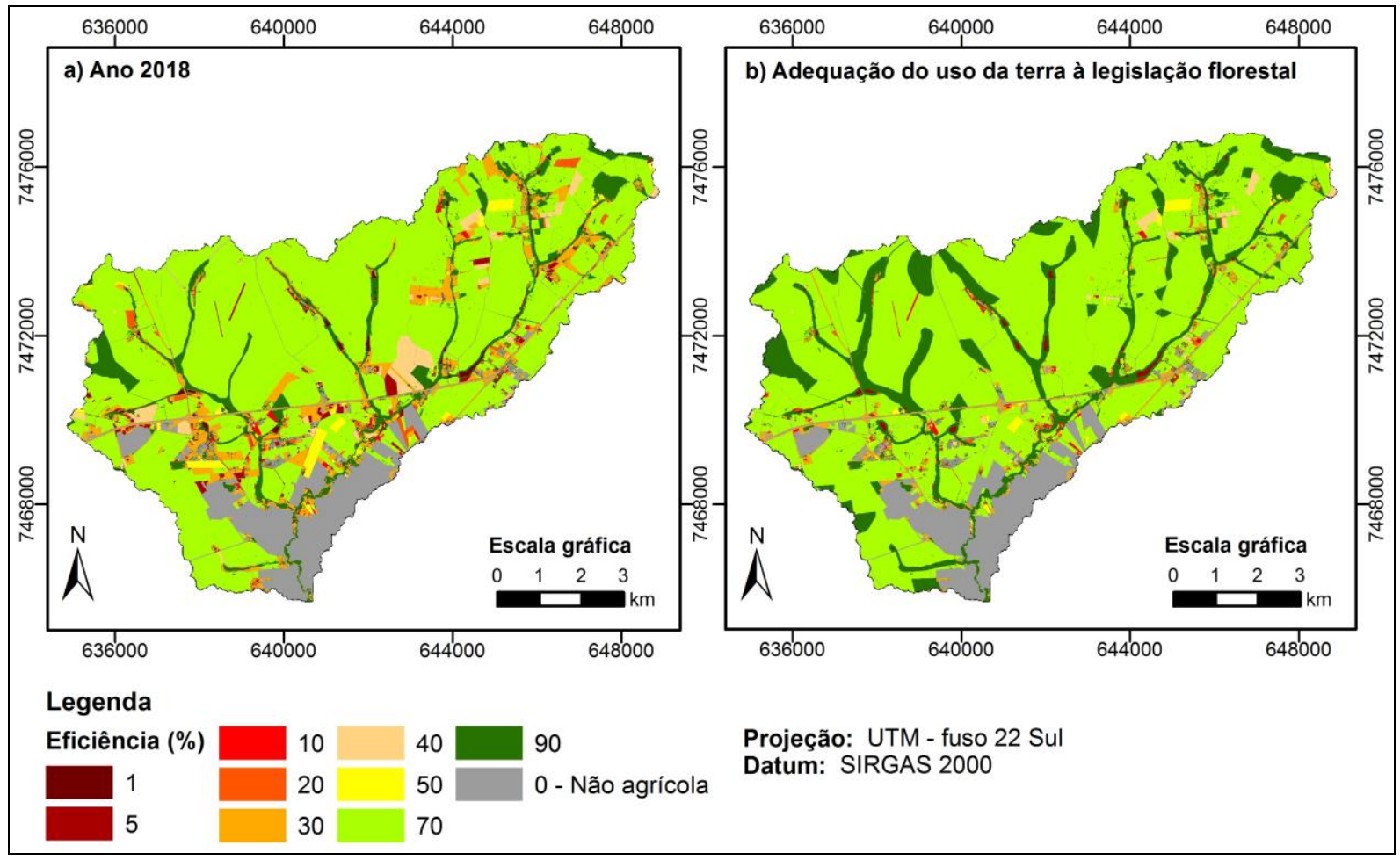

Organização - dos Autores (2019). 
A comparação entre os mapas da Figura 4 revela a redução das áreas agrícolas sem práticas conservacionistas no cenário LF em relação a 2018, de 11,52 \% para 5,13 \% da área de estudo, a estabilização das áreas cultivadas em nível e terraceadas, o aumento das pastagens terraceadas de $17,39 \%$ para 21,37 \%, e a quase duplicação das áreas florestais em APP e RL, de 8,45 \% para 15,5 \%. A importância das práticas de conservação do solo no controle da erosão foi demonstrada por Haiyan e Liying (2017) na bacia do Rio Shuangyang, região nordeste da China. A simulação com o modelo WaTEM/SEDEM comparou as práticas conservacionistas existentes (terraceamento e plantio em nível) com o cenário sem medidas de conservação do solo, e evidenciou o aumento do aporte de sedimentos de 12.965 t.ano $^{-1}$ para 18.339 t.ano $^{-1}$. A taxa média de exportação de sedimentos das 19 sub-bacias aumentou de 1.574 t.ano-1 para 2.698 t.ano ${ }^{-1}$ no cenário sem práticas de conservação, e a taxa de aporte de sedimentos, de $17 \%$ para $29 \%$. Os índices de erosão observados na bacia hidrográfica, entretanto, foram bastante superiores aos limites toleráveis, pois as áreas terraceadas e cultivadas em nível que constituem áreas de deposição de sedimentos ocupavam, respectivamente, 0,7 e $2,5 \%$, e o plantio morro abaixo representava $57,4 \%$ de sua área total.

No cenário LF, a intensificação do uso de práticas conservacionistas e o aumento das áreas florestais promoveram o aumento da eficiência de retenção de sedimentos das parcelas (Figura 5). Os valores médios de ERS do ano 2018 e do cenário LF foram, respectivamente, 57,99 \% e 63,39 \%. A área de contato das pastagens e florestas, analisadas em conjunto, com os demais usos da terra, também aumentou de $604,48 \mathrm{~km}$ em 2018 para $617,64 \mathrm{~km}$ no cenário LF. Consequentemente, houve o aumento da retenção de sedimentos no contato dos usos agrícolas e urbanos com as florestas e pastagens, e nas parcelas, dado o aumento da ERS média.

O aumento da área média das parcelas pressupõe redução da fragmentação da paisagem e maior suscetibilidade à erosão e ao transporte de sedimentos, pois seu comprimento de rampa se torna maior, salvo quando elas se estendem perpendicularmente ao declive. Considerando as parcelas agrícolas de área maior que 1 ha para eliminar os pixels isolados, a área de estudo possuía 465 parcelas de área média 8,97 ha em 2018. No cenário LF, o número de parcelas reduziu para 416 ha e sua área aumentou para 9,12 ha. Entretanto, embora tenha havido redução da fragmentação da paisagem, o fator LS médio reduziu de 5,10 em 2018 para 4,75 no cenário LF, e seus valores máximos passaram de 246,47 para 202,28, denotando menor suscetibilidade à erosão no cenário LF em razão da diminuição da área de contribuição dos pixels das áreas agrícolas, devido ao aumento da eficiência de retenção de sedimentos e da conectividade das parcelas.

A relação do tamanho das parcelas e do padrão espacial do uso da terra com as taxas de erosão e de exportação de sedimentos foi evidenciada por Van Rompaey; Krasa; Dostal (2007) na bacia de drenagem Orlice, República Tcheca. Os cenários simulados pelo modelo WaTEM/SEDEM mostraram que a redução no tamanho das parcelas decorrente do fim da coletivização das terras após o término do regime comunista promoveu a diminuição das taxas médias anuais de erosão e de aporte de sedimentos, embora essa redução não tenha sido linear quando comparada aos diferentes tamanhos das parcelas. Tal fato se deve à redução do comprimento de rampa das vertentes e ao aumento do número de limites entre as parcelas, onde os sedimentos são retidos. A conversão de terras agrícolas em pastagens de forma aleatória ou nas áreas de maior declividade também fez as taxas de erosão e de aporte de sedimentos reduzirem. A maior diminuição foi verificada no cenário de implantação de pastagens nos relevos mais declivosos, que provocaram a redução do fator $\mathrm{C}$ da RUSLE.

O padrão espacial ou estrutura da ocupação agrícola tem, juntamente com o uso da terra e o manejo do solo, importância fundamental no controle da produção e da retenção de sedimentos nas bacias. O cenário de otimização do uso da terra e de sua estrutura espacial simulado por Shi et al. (2012) na bacia do Rio Wangjiaqiao, China, com aumento da fragmentação da paisagem, mostrou a redução da taxa de erosão anual em $21,1 \%$ e da exportação de sedimentos em $42,9 \%$, pois a introdução de florestas na paisagem promoveu a redução das taxas de erosão e do escoamento superficial nas áreas agrícolas encosta abaixo. Ademais, nessas condições, o solo erodido das áreas agrícolas tem maior probabilidade de ser retido pelas florestas localizadas em níveis topográficos inferiores, dada a menor conectividade entre as áreas-fontes de sedimentos e os rios. A fragmentação da paisagem, no entanto, teve efeito contrário na exportação de sedimentos pela bacia Kali, Hungria, conforme constatado por Jordan et al. (2005) em análise histórica dos processos erosivos realizada com o modelo WaTEM/SEDEM. O aumento do aporte de sedimentos no exutório da bacia nos períodos históricos recentes, sobretudo durante o regime comunista, se comparados às condições de uso da terra dos séculos XVIII, XIX e início do século XX, resultou do crescimento do número de parcelas agrícolas e da redução de sua área, que abriu corredores para o transporte de sedimentos à rede de drenagem. As taxas de erosão, contudo, reduziram no decorrer do período histórico, consequência da substituição do cultivo agrícola pelas pastagens e campos.

Caminhos de Geografia $\quad$ Uberlândia-MG $\quad$ v. 21, n. $78 \quad$ Dez/2020 $\quad$ p. 117-137 Página 129


A Tabela 3 apresenta os coeficientes kTc calibrados das chuvas individuais e dos conjuntos de chuvas por faixa de erosividade, assim como os coeficientes de eficiência Nash-Suttclife e RSR obtidos para os respectivos conjuntos.

Tabela 3 - Calibração dos coeficientes kTc dos conjuntos de chuvas de erosividades semelhantes e coeficientes de eficiência do modelo WaTEM/SEDEM.

\begin{tabular}{|c|c|c|c|c|c|c|c|}
\hline \multirow[b]{2}{*}{$\begin{array}{l}\text { Data do } \\
\text { evento }\end{array}$} & \multirow{2}{*}{$\begin{array}{c}\text { Erosividade } \\
\text { (MJ.mm.ha- } \\
\left.{ }^{1} \cdot \mathrm{h}^{-1}\right)\end{array}$} & \multicolumn{2}{|c|}{ Chuvas individuais } & \multicolumn{2}{|c|}{ Conjunto } & \multirow{2}{*}{$\begin{array}{l}\text { Nash- } \\
\text { Suttclife }\end{array}$} & \multirow[b]{2}{*}{ RSR } \\
\hline & & $\begin{array}{c}\text { kTc baixo } \\
(\mathrm{m})\end{array}$ & $\begin{array}{c}\text { kTc alto } \\
\text { (m) }\end{array}$ & kTc baixo (m) & $\begin{array}{c}\text { kTc alto } \\
\text { (m) }\end{array}$ & & \\
\hline $28 / 02 / 2018$ & 61,68 & 23 & 77 & \multirow{2}{*}{23} & \multirow{2}{*}{77} & \multirow{2}{*}{0,999} & \multirow{2}{*}{0,011} \\
\hline $13 / 03 / 2018$ & 61,04 & 23,5 & 77 & & & & \\
\hline $20 / 02 / 2018$ & 119,12 & 18,5 & 57 & \multirow{2}{*}{18,5} & \multirow{2}{*}{60,5} & \multirow{2}{*}{0,965} & \multirow{2}{*}{0,187} \\
\hline 20/09/2018 & 107,63 & 18,5 & 61,5 & & & & \\
\hline $25 / 03 / 2018$ & 324,88 & 24,5 & 80 & - & - & - & - \\
\hline
\end{tabular}

Curiosamente, os valores dos coeficientes $\mathrm{kTc}$ das chuvas individuais de maior e de menor faixa de erosividade foram semelhantes, e superiores aos coeficientes referentes às chuvas de erosividade média. No evento de chuva de 20/09/2018, o fator C médio da área de estudo foi o maior entre as chuvas analisadas $(0,263)$ e a erosão simulada foi de $25,667 \mathrm{t}$. Para que o aporte de sedimentos simulado no exutório se igualasse ao observado, e considerando a maior disponibilidade de sedimentos erodidos, os coeficientes kTc calibrados foram menores. Já no evento de chuva de 20/02/2018, embora tivesse o menor fator $C$ médio $(0,142)$, a maior erosividade da chuva fez com que a taxa de erosão simulada fosse de 18,028 t, superior à dos eventos de 28/02 e 13/03/2018 e os coeficientes kTc calibrados tivessem menores valores para que o aporte de sedimentos simulado se igualasse ao observado. Essas constatações apontam a necessidade de realizar mais medições em campo em eventos reais de chuva, de modo a melhorar a calibração do modelo.

Os totais de sedimentos erodidos, depositados e exportados da bacia do Ribeirão São Domingos, simulados pelo modelo WaTEM/SEDEM nas condições de uso da terra de 2018 e cenário LF e em diferentes faixas de erosividade da chuva são apresentados na Tabela 4.

Tabela 4 - Balanço de erosão e aporte de sedimentos em chuvas de diferentes erosividades e condições de uso da terra.

\begin{tabular}{clcccc}
\hline $\begin{array}{c}\text { Erosividade da } \\
\text { chuva } \\
\left(\mathbf{M J} \cdot \mathbf{m m} \cdot \mathbf{h a}^{-1} \cdot \mathbf{h}^{-1}\right)\end{array}$ & \multicolumn{1}{c}{ Ano / Cenário } & $\begin{array}{c}\text { Produção de } \\
\text { sedimentos (t) }\end{array}$ & $\begin{array}{c}\text { Deposição de } \\
\text { sedimentos (t) }\end{array}$ & $\begin{array}{c}\text { Aporte de } \\
\text { sedimentos (t) }\end{array}$ & $\begin{array}{c}\text { Taxa de } \\
\text { aporte de } \\
\text { sedimentos } \\
(\%)\end{array}$ \\
\hline \multirow{2}{*}{61,68} & 2018 & 5,723 & 4,106 & 1,617 & 28,25 \\
& Legislação florestal & 4,702 & 3,434 & 1,268 & 26,97 \\
\hline \multirow{2}{*}{119,12} & 2018 & 10,608 & 7,891 & 2,717 & 25,61 \\
& Legislação florestal & 8,855 & 6,715 & 2,140 & 24,17 \\
\hline \multirow{2}{*}{324,88} & Le18 & 30,145 & 21,515 & 8,630 & 28,62 \\
& Legislação florestal & 24,852 & 18,019 & 6,833 & 27,49 \\
\hline
\end{tabular}

Organização - dos Autores (2019).

A produção de sedimentos simulada de ambas as condições de uso da terra foi proporcional à erosividade da chuva, apesar de ter sido determinada pelo conjunto dos demais fatores da RUSLE. Já a deposição e, consequentemente, o aporte de sedimentos no exutório, foram influenciados pela capacidade de transporte de sedimentos (TC), determinada pelos coeficientes kTc calibrados e pelos fatores erosividade da chuva, erodibilidade do solo, declividade e comprimento de rampa da RUSLE, sendo que este último fator é modificado pela eficiência de retenção de sedimentos das parcelas e pela sua conectividade. A maior a capacidade de transporte (TC) implica em menor taxa de deposição e maior aporte de sedimentos no exutório das bacias hidrográficas. Não foi possível comparar os resultados deste trabalho com os obtidos por outros pesquisadores com o modelo WaTEM/SEDEM, pois a aplicação do modelo foi adaptada para a simulação de produção e aporte de

$\begin{array}{lllll}\text { Caminhos de Geografia } \quad \text { Uberlândia-MG } & \text { v. 21, n. } 78 & \text { Dez/2020 } & \text { p. 117-137 Página } 130\end{array}$


sedimentos em eventos individuais de chuvas intensas. Cabe destacar que ele foi concebido para a modelagem dos valores médios anuais desses processos e aplicado em ambientes distintos da área de estudo nos aspectos climáticos, pedológicos, geomorfológicos e de uso da terra.

A adequação das APP e RL das propriedades rurais à legislação florestal brasileira promoveu a redução da erosão devido ao aumento da cobertura florestal, do uso de práticas conservacionistas, da ERS, das áreas de transição entre outros usos da terra e as florestas ou pastagens, e à redução do fator LS médio. Já o aumento da deposição de sedimentos nas vertentes e fundos de vale, com a consequente redução da exportação de sedimentos no exutório, se deu em razão das maiores ERS e conectividade das parcelas e do aumento das áreas de baixo kTc, a despeito do aumento da área média das parcelas agrícolas. Resultados semelhantes foram obtidos por Liu e Fu (2016) na bacia Nianzhuang, localizada em área montanhosa e declivosa do Platô Loess, China, e fortemente afetada por erosão em voçorocas. Nesta bacia, algumas atividades antrópicas, tais como o reflorestamento, a construção de barragens, de terraços, e o cultivo em planícies represadas ao redor dos rios provocaram a redução da taxa de exportação de sedimentos, pois interromperam ou enfraqueceram o seu transporte entre as áreas-fontes e a rede de drenagem. Em simulação realizada com o modelo WaTEM/SEDEM na escala anual, do total de $1.020 \mathrm{t}$ de sedimentos produzidos, $892 \mathrm{t}$ foram retidos em áreas agrícolas represadas e em outros reservatórios, e $128 \mathrm{t}$ foram exportados aos rios. Keesstra et al. (2009) evidenciaram, por meio do modelo WaTEM/SEDEM, a redução das taxas de erosão e do aporte de sedimentos no exutório das sub-bacias do Rio Dragonja, sudoeste da Eslovênia, no período 1954-1975, com continuidade do processo até o ano 2002, resultado da redução populacional e do abandono das áreas agrícolas, que provocaram a regeneração da vegetação arbórea. Na sub-bacia do Dragonja superior, a redução do aporte de sedimentos no período 1954-2002 foi de $76 \%$, dado o aumento da área florestada de $29 \%$ para $73 \%$. Na sub-bacia Rokava, mais intensamente ocupada pela agricultura e pastagem devido à posição geográfica favorável e relevo menos declivoso, a redução do aporte de sedimentos foi de 53 \% no mesmo período.

As taxas de aporte de sedimentos foram menores nas chuvas de erosividade $119,12 \mathrm{MJ} \cdot \mathrm{mm} \cdot \mathrm{ha}^{-1} \cdot \mathrm{h}^{-1}$ devido aos valores mais baixos de kTc obtidos por calibração, se comparados às chuvas de maior e menor erosividade, pelas razões abordadas anteriormente.

No cenário LF, a alocação da vegetação arbórea nas faixas marginais aos cursos d'água como APP teve a finalidade de protegê-los da erosão marginal, manter o regime hídrico nas estações secas e reter os sedimentos transportados de montante, além de cumprir a Lei no 12.651/2012. Essa vegetação foi eficiente na retenção de sedimentos e fez com que as áreas simuladas de deposição aumentassem de 215 ha em 2018 para 247,36 ha no cenário LF. Entretanto, a redução da perda de solo por erosão e da taxa de aporte de sedimentos no exutório neste cenário está relacionada principalmente às mudanças no uso e manejo do solo e à implantação das práticas conservacionistas, entre as quais se incluem o terraceamento, o plantio em nível e a própria vegetação arbórea, que promoveram o aumento da ERS nas parcelas.

Esta característica foi observada por Verstraeten et al. (2003), que utilizaram o modelo WaTEM/SEDEM em três bacias hidrográficas na região de Flandres, Bélgica, em diferentes cenários de uso e manejo do solo, e verificaram que as maiores reduções nas taxas de erosão e de aporte de sedimentos ocorreram quando se adotaram medidas para conter a produção de sedimentos na fonte, como a conversão de áreas agrícolas altamente erodíveis em pastagens ou florestas, em detrimento das medidas alocadas distantes das áreas-fonte de sedimentos, como as faixas gramadas nas proximidades dos rios ou no final das parcelas agrícolas de alta suscetibilidade à erosão, ou mesmo os açudes e bacias de retenção de sedimentos, que foram menos eficientes em promover a sua deposição e controlar sua exportação no exutório da bacia. Feng et al. (2010) também evidenciaram, na bacia Yangou, localizada no Platô Loess na China, a redução do grau médio de erosão de 2,09 para 1,6 entre os anos 1990 e 2005 como resultado da implantação do projeto Grain-for-Green pelo governo central chinês. Sendo os terrenos de declividade superior a $25^{\circ}$ as principais fontes de sedimentos, a conversão do uso agrícola destas áreas em pastagens ou áreas agrícolas terraceadas reduziu moderadamente as taxas de erosão, ao passo que a conversão em bosques ou arbustos de terrenos com declividade entre 15 e 25 minimizou o processo erosivo, sem contar a organização do padrão de uso da terra, fundamental no controle da perda de solo por erosão.

Da mesma forma, Verstraeten et al. (2006) avaliaram a eficiência de faixas de vegetação ripária de 20 metros de largura como filtros de sedimentos em diferentes escalas e verificaram que em parcelas experimentais instaladas em vertentes, a eficiência de retenção foi de $78 \%$, enquanto na escala de bacia hidrográfica de diferentes tamanhos, reduziu para 35 a $40 \%$ devido à convergência do fluxo nas vertentes, que se concentra e cruza partes da zona ripária, podendo submergir a vegetação, 
tombá-la ou quebrá-la; e do escoamento concentrado através de rodovias e do sistema de drenagem das cidades localizadas nas margens dos rios. Para reduzir a produção de sedimentos, os autores propuseram algumas medidas nas áreas agrícolas, como a mudança do uso e manejo das áreas mais suscetíveis à erosão, a implantação de corredores gramados de escoamento, entre outras.

O padrão espacial simulado de erosão e deposição de sedimentos dos anos 2018 e cenário legislação florestal no evento de chuva de maior erosividade é apresentado na Figura 6.

Figura 6 - Erosão e deposição de sedimentos simulada com o modelo WaTEM/SEDEM em chuva de erosividade 324,88 MJ.mm.ha- ${ }^{-1} \cdot h^{-1}:$ a) ano 2018; b) adequação à legislação florestal brasileira.

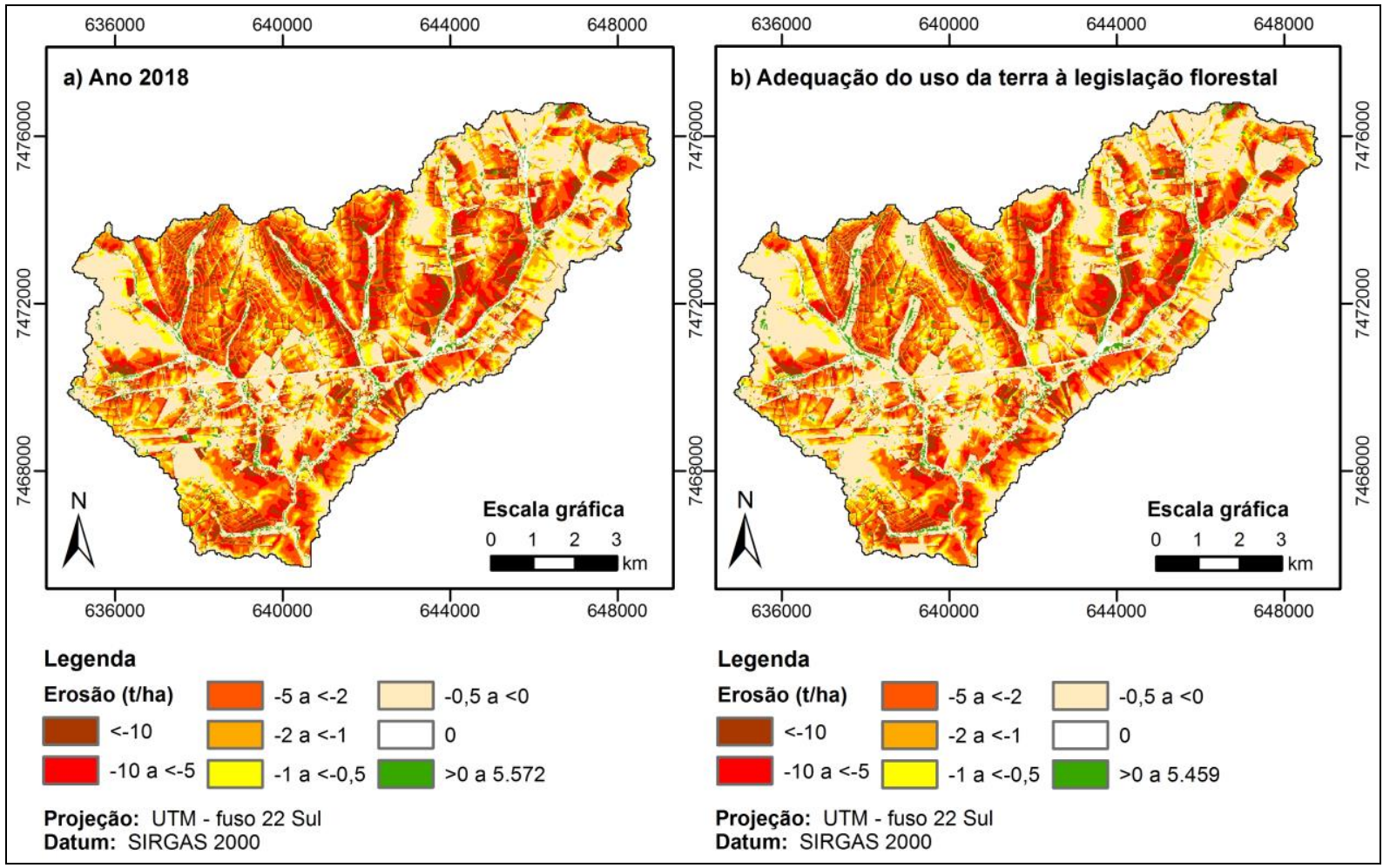

Organização - dos Autores (2019).

O padrão espacial de erosão simulado nas áreas agrícolas e urbanas foi semelhante nas duas condições de uso e manejo do solo, mas o processo erosivo teve menor intensidade nas APP e nas áreas convertidas em RL no cenário LF. Observou-se também o aumento das taxas de erosão na zona urbana e nas pastagens nos terços médio e inferior das vertentes em ambas as condições simuladas em razão do aumento do comprimento de rampa, apesar de serem áreas de reduzida erosão e pequeno transporte de sedimentos, pois o modelo WaTEM/SEDEM compreende esses usos da terra como parcelas únicas e não as segmenta, o que constitui uma limitação do modelo.

Nas parcelas agrícolas, a taxa de erosão simulada foi maior em seus limites inferiores devido ao maior fator L, quando na realidade constituem áreas de deposição de sedimentos, sobretudo no contato de parcelas ocupadas por outros usos da terra com as florestas e pastagens. As altas taxas de erosão, superiores a 10 t.ha $^{-1}$, foram observadas também nas áreas determinadas pelo MDE como de convergência do escoamento, que apresentaram valores elevados do fator topográfico. Liu e Fu (2016) observaram, na bacia Nianzhuang, China, que as principais fontes de sedimentos são as áreas localizadas nas encostas declivosas diretamente conectadas aos rios, reservatórios e planícies de inundação utilizadas para a agricultura, nas quais a diferença entre saída e entrada de sedimentos atinge valores positivos elevados. Konečná et al. (2020) observaram na pequena bacia de $\mathrm{Na}$ Hrebelci, situada nas terras altas da Boêmia-Morávia, República Tcheca, a partir da modelagem de erosão com o WaTEM/SEDEM, que as principais fontes de sedimentos foram as áreas agrícolas localizadas nas proximidades da rede de drenagem, e que os sedimentos produzidos em áreas mais distantes foram, em sua maioria, depositados nas vertentes devido à presença de usos da terra que reduziram o volume do escoamento superficial. 
Na área de estudo, as áreas de deposição de sedimentos simuladas se localizaram nos fundos de vale e planícies aluviais devido à quebra do relevo e à redução da declividade; nos limites entre as parcelas agrícolas, logo abaixo deles no sentido do declive, em razão do início de uma nova parcela; e em áreas planas dos interflúvios e próximas aos divisores de águas, nos quais a erosão e a capacidade de transporte de sedimentos assumem valores baixos. Esses padrões de deposição concordam com o observado por Krasa et al. (2010). Embora a modelagem tenha computado o efeito dos terraços na ERS das parcelas, não os levou em consideração como barreiras mecânicas à retenção do escoamento e de sedimentos, tal como o fez com os limites inferiores das parcelas.

A erodibilidade do solo teve influência limitada na estimativa da erosão. Áreas de alta erodibilidade da porção nordeste da bacia hidrográfica (Figura 2.b) apresentaram baixas taxas devido à ocupação pelas pastagens e florestas, enquanto nos canaviais situados nas proximidades da nascente do Ribeirão São Domingos o processo erosivo foi maior, apesar da erodibilidade baixa.

A adaptação do modelo WaTEM/SEDEM para a escala temporal de eventos de chuva permitiu a simulação da erosão e deposição de sedimentos na bacia, calibradas pelo aporte de sedimentos no exutório, mas a estrutura temporal dos hidrogramas foi desconsiderada pelo fato de o modelo adotar um valor único de $\mathrm{R}$, embora seu cálculo considere a maior intensidade da chuva em 30 minutos.

\section{CONSIDERAÇÕES FINAIS}

As simulações realizadas com o modelo WaTEM/SEDEM comprovaram a necessidade de analisar em conjunto os fatores responsáveis pela desagregação, transporte e deposição de sedimentos que definem o processo erosivo, ou seja, as características das chuvas, do solo, do relevo, do uso da terra, das práticas de conservação do solo, a estrutura hidrológica e da paisagem e a disposição das parcelas agrícolas.

O cenário simulado de adequação do uso e manejo do solo à legislação florestal brasileira apresentou, em relação ao ano 2018 e em eventos de chuva de diferentes erosividades, menor taxa de erosão, maior deposição de sedimentos nas vertentes e fundos de vale e menor aporte de sedimentos no exutório, resultados que podem ser explicados pela redução do fator $\mathrm{C}$ com o aumento da vegetação nas APP e RL; pelo aumento do uso de práticas conservacionistas e, consequentemente, da eficiência de retenção de sedimentos das parcelas; pelo aumento das áreas de contato das parcelas de pastagens e vegetação nativa com outros usos da terra, evidenciada pelo parâmetro conectividade das parcelas; pela redução do fator comprimento de rampa, em decorrência da maior ERS e conectividade das parcelas; e pela localização da vegetação arbórea nos fundos de vale, que favorecem a deposição de sedimentos. Esses resultados foram observados a despeito do aumento da área média das parcelas agrícolas e da redução do seu número, isto é, da menor fragmentação da paisagem.

Este trabalho também adaptou o modelo WaTEM/SEDEM para a simulação do balanço de erosão e do aporte de sedimentos em eventos de chuvas intensas, os quais ocorrem com menor frequência mas são responsáveis, nas regiões tropicais, pelas maiores taxas de erosão e de transporte de sedimentos nas bacias hidrográficas. Em relação ao fator $P$ da RUSLE, a pesquisa levou em consideração os efeitos das práticas conservacionistas na parametrização da eficiência de retenção de sedimentos das parcelas.

\section{REFERÊNCIAS}

ALATORRE, L. C.; BEGUERÍA, S.; GARCÍA-RUIZ, J. M. Regional scale modeling of hillslope sediment delivery: A case study in the Barasona Reservoir watershed (Spain) using WATEM/SEDEM. Journal of Hydrology, Amsterdam, v. 391, n. 1-2, p. 109-123, 2010. https://doi.org/10.1016/j.jhydrol.2010.07.010

BERTOL, I.; SCHICK, J.; BATISTELA, O. Razão de perdas de solo e fator C para as culturas de soja e trigo em três sistemas de preparo em um Cambissolo Húmico Alumínico. Revista Brasileira de Ciência do Solo, Viçosa, MG, v. 25, n. 2, p. 451-461, 2001. https://doi.org/10.1590/S0100$\underline{06832001000200021}$

Razão de perdas de solo e fator $C$ para milho e aveia em rotação com outras culturas em três tipos de preparo do solo. Revista Brasileira de Ciência do Solo, Viçosa, MG, v. 26, n. 2, p. 545-552, 2002. https://doi.org/10.1590/S0100-06832002000200029 
BRASIL. Lei n. 12.651, de 25 de maio de 2012. Dispõe sobre a proteção da vegetação nativa; altera as Leis nos 6.938, de 31 de agosto de 1981, 9.393, de 19 de dezembro de 1996, e 11.428, de 22 de dezembro de 2006; revoga as Leis nos 4.771, de 15 de setembro de 1965, e 7.754, de 14 de abril de 1989, e a Medida Provisória no 2.166-67, de 24 de agosto de 2001; e dá outras providências. Diário Oficial da União, Brasília, DF, ano CXLIX, n. 102, p. 1-8, 28 maio 2012. Seção 1.

Ministério da Agricultura. Serviço Florestal Brasileiro. Sistema Nacional de Cadastro Ambiental Rural (SICAR): Base de downloads, Santa Cruz do Rio Pardo. 2018. Disponível em: http://www.car.gov.br/publico/municipios/downloads?sigla=SP. Acesso em: 18 nov. 2018.

CARVALHO, N. O. et al. Guia de práticas sedimentométricas. Brasília, DF: ANEEL, 2000.

CAVALIERI, A. Estimativa da adequação de uso das terras na quadrícula de Moji Mirim (SP) utilizando diferentes métodos. 1998. 112 f. Tese (Doutorado em Engenharia Agrícola) - Faculdade de Engenharia Agrícola, Universidade Estadual de Campinas, Campinas, 1998.

DEMARCHI, J. C. Modelagem das transformações no uso da terra, de processos erosivos e de escoamento superficial na bacia hidrográfica do Ribeirão São Domingos, município de Santa Cruz do Rio Pardo - SP. 2019. 536 f. Tese (Doutorado em Geografia) - Faculdade de Ciências e Tecnologia, Universidade Estadual Paulista, Presidente Prudente, 2019.

DENARDIN, J. E. Erodibilidade do solo estimada por meio de parâmetros físicos e químicos. 1990. 81 f. Tese (Doutorado em Agronomia/Solos e Nutrição de Plantas) - Escola Superior de Agricultura "Luiz de Queiroz", Universidade de São Paulo, Piracicaba, 1990.

DESMET, P. J. J.; GOVERS, G. A GIS procedure for automatically calculating the USLE LS factor on topographically complex landscape units. Journal of Soil and Water Conservation, Ankeny, v. 51, n. 5, p .427-433, 1996.

DIDONÉ, E. J.; MINELLA, J. P. G.; EVRARD, O. Measuring and modelling soil erosion and sediment yields in a large cultivated catchment under no-till of Southern Brazil. Soil \& Tillage Research, Amsterdam, v. 174, p. 24-33, 2017. https://doi.org/10.1016/j.still.2017.05.011

DIGITALGLOBE. Imagem Geoeye-1 de 11/12/2017. 2017a. Disponível em: Google Earth Pro [programa de computador]. Acesso em: 16 jan. 2019.

Imagem Worldview-2 de 16/07/2017. 2017b. Disponível em: Google Earth Pro [programa de computador]. Acesso em: 16 jan. 2019.

DONZELI, P. L. et al. Técnicas de Sensoriamento Remoto aplicadas ao diagnóstico básico para planejamento e monitoramento de Microbacias Hidrográficas. Documentos IAC, Campinas, n. 29, p. 91-119, 1992.

DURIGON, V. L. et al. NDVI time series for monitoring RUSLE cover management factor in a tropical watershed. International Journal of Remote Sensing, Abingdon, v. 35, n. 2, p. 441-453, 2014. https://doi.org/10.1080/01431161.2013.871081

EMBRAPA - Empresa Brasileira de Pesquisa Agropecuária. Sistema brasileiro de classificação de solos. 3 ed. Rio de Janeiro: Embrapa Solos, 2013.

FENG, X. et al. Modeling soil erosion and its response to land-use change in hilly catchments of the Chinese Loess Plateau. Geomorphology, Amsterdam, v, 118, n. 3-4, p. 239-248, 2010. https://doi.org/10.1016/i.geomorph.2010.01.004

FOSTER, G. R. et al. Conversion of the Universal Soil Loss Equation to SI metric units. Journal of Soil and Water Conservation, Ankeny, v. 36, n. 6, p. 355-359, 1981.

GALDINO, S. Estimativa da perda de terra sob pastagens cultivadas em solos arenosos da bacia hidrográfica do Alto Taquari - MS/MT. 2012. $99 \mathrm{f}$. Tese (Doutorado em Engenharia Agrícola) - Faculdade de Engenharia Agrícola, Universidade Estadual de Campinas, Campinas, 2012.

GONÇALVES, J. L. M. Conservação do solo. In: GONÇALVES, J. L. M.; STAPE, J. L. (Ed.) Conservação e cultivo de solos para plantações florestais. Piracicaba: IPEF, 2002. p. 47-129.

GOVERS, G. Rill erosion on arable land in Central Belgium. Catena, Amsterdam, v. 18, n. 2, p. 133155, 1991. https://doi.org/10.1016/0341-8162(91)90013-N 
GUERRA, A. J. T. Processos erosivos nas encostas. In: GUERRA, A. J. T.; CUNHA, S. B. (Org.) Geomorfologia: uma atualização de bases e conceitos. 6 ed. Rio de Janeiro: Bertrand Brasil, 2005. p. 149-209.

HAIYAN, F.; LIYING, S. Modelling soil erosion and its response to the soil conservation measures in the black soil catchment, Norteastern China. Soil \& Tillage Research, Amsterdam, v. 165, p. 23-33, 2017. https://doi.org/10.1016/j.still.2016.07.015

HAREGEWEYN, N. et al. Assessing the performance of a spatially distributed soil erosion and sediment delivery model (WATEM/SEDEM) in Northern Ethiopia. Land Degradation \& Development, Chichester, v. 24, n. 2, p. 188-204, 2013. https://doi.org/10.1002/ldr.1121

IBGE - Instituto Brasileiro de Geografia e Estatística. Bases e referenciais - Bases cartográficas Malhas digitais - 2015: Unidades da Federação e Municípios. Disponível em: ftp://geoftp.ibge.gov.br/organizacao do territorio/malhas territoriais/malhas municipais/municipio 20 15/Brasil/BR/. Acesso em: 10 dez. 2018.

. Mapa de vegetação do Brasil. Rio de Janeiro: IBGE, 2004. Escala: 1:500.000.

INPE - Instituto Nacional de Pesquisas Espaciais. Imagem CBERS-4, sensor MUX, órbita/ponto 158/126 de 21/01/2018 e 14/03/2018. 2018a. Disponível em: http://www.dgi.inpe.br/catalogo/. Acesso em: 22 jan. 2019.

Imagem CBERS-4, sensor PAN, órbita/ponto 158/126 de 16/02/2018 e 12/09/2018. $2018 \mathrm{~b}$. Disponível em: http://www.dgi.inpe.br/catalogo/. Acesso em: 22 jan. 2019.

Imagem Landsat-8, sensor OLI, órbita/ponto 221/076 de 10/09/2017, 01/02/2018 e 17/02/2018. 2017, 2018c. Disponível em: http://www.dgi.inpe.br/catalogo/. Acesso em: 21 jan. 2019.

Imagem ResourceSat-2, sensor LISS III, órbita/ponto 328/094 de 12/03/2018 e 23/05/2018. 2018d. Disponível em: http://www.dgi.inpe.br/catalogo/. Acesso em: 20 jan. 2019.

IPT - Instituto de Pesquisas Tecnológicas (São Paulo). Mapa Geológico do Estado de São Paulo. São Paulo: IPT, 1981. Escala: 1:500.000.

JORDAN, G. et al. Historical land use changes and their impact on sediment fluxes in the Balaton basin (Hungary). Agriculture Ecosystems \& Environment, Amsterdam, v. 108, n. 2, p. 119-133, 2005. https://doi.org/10.1016/j.agee.2005.01.013

KEESSTRA, S. D. et al. Changing sediment dynamics due to natural reforestation in the Dragonja catchment, SW Slovenia. Catena, Amsterdam, v. 78, n. 1, p. 60-71, 2009. https://doi.org/10.1016/i.catena.2009.02.021

KONEČNÁ, J. et al. Using WaTEM/SEDEM and HEC-HMS models for the simulation of episodic hydrological and erosion events in a small agricultural catchment. Soil and Water Research, Prague, v. 15, n. 1, p. 18-29, 2020. https://doi.org/10.17221/202/2018-SWR

KRASA, J. et al. Predicting spatial patterns of sediment delivery and impacts of land-use scenarios on sediment transport in Czech catchments. Land Degradation \& Development, v. 21, n. 4, p. 367-375, 2010. https://doi.org/10.1002/ldr.959

LIU, Y.; FU, B. Assessing sedimentological connectivity using WATEM/SEDEM model in a hilly and gully watershed of the Loess Plateau, China. Ecological Indicators, Amsterdam, v. 66, n. , p. 259268, 2016. https://doi.org/10.1016/j.ecolind.2016.01.055

LOPES, F. et al. Utilização de P-Index em uma bacia hidrográfica através de técnicas de geoprocessamento. Revista Brasileira de Engenharia Agrícola e Ambiental, Campina Grande, v. 11, n. 3, p. 312-317, 2007. https://doi.org/10.1590/S1415-43662007000300011

MARQUES, J. F.; LOMBARDI NETO, F.; BACELLAR, A. A. A. Erosão do solo: indicadores físicos e econômicos. In: MARQUES, J. F.; SKORUPA, L. A.; FERRAZ, J. M. G. (Ed.) Indicadores de sustentabilidade em agroecossistemas. Jaguariúna: Embrapa Meio Ambiente, 2003. p. 129-153.

MIRANDA, M. J. et al. Clima dos municípios paulistas. CEPAGRI/UNICAMP, 2005. http://www.cpa.unicamp.br/outras-informacoes/clima-dos-municipios-paulistas.html. Acesso em: 19 de dezembro de 2019. 
MORIASI, D. N. et al. Model evaluation guidelines for systematic quantification of accuracy in watershed simulations. Transactions of the ASABE, Saint Joseph, v. 50, n. 3, p. 885-900, 2007. https://doi.org/10.13031/2013.23153

NASA - National Aeronautics and Space Administration. Modelo Digital de Elevação ASTER GDEM v. 2. 2011. Disponível em: https://earthdata.nasa.gov/. Acesso em: 15 jun. 2019.

NATURAL EARTH. Shapefile dos países. 2009. Disponível em: https://www.naturalearthdata.com/downloads/. Acesso em: 10 jan. 2020.

NOTEBAERT, B. et al. WaTEM / SEDEM version 2006: manual. Leuven: KU Leuven, 2006. Disponível

http://geo.kuleuven.be/geography/modelling/erosion/watemsedem2006/manual watemsedem.pdf.

Acesso em: 16 de junho de 2017.

PALHARES, J. C. P. et al. Medição da vazão em rios pelo método do flutuador. Concórdia: Embrapa Suínos e Aves, 2007. (Comunicado Técnico, 455).

PIRES, F. R.; SOUZA, C. M. Práticas mecânicas de conservação do solo e da água. Viçosa, MG: [s.n.], 2003.

POLETO, C. Bacias hidrográficas urbanas. In:

hídricos. Rio de Janeiro: Interciência, 2014. p. 29-47.

(Org.) Bacias hidrográficas e recursos

PROCHNOW, D. et al. Razão de perdas de terra e fator $C$ da cultura do cafeeiro em cinco espaçamentos, em Pindorama (SP). Revista Brasileira de Ciência do Solo, Viçosa, MG, v. 29, n. 1, p. 91-98, 2005. https://doi.org/10.1590/S0100-06832005000100010

RENARD, K. G. et al. (Coord.) Predicting soil erosion by water: guide to conservation planning with Revised Universal Soil Loss Equation (RUSLE). Washington: US Gov. Print Office, 1997. (Agriculture Handbook, 703).

ROLIM, G. S. et al. Classificação climática de Köppen e de Thornthwaite e sua aplicabilidade na determinação de zonas agroclimáticas para o Estado de São Paulo. Bragantia, Campinas, v. 66, n. 4, p. 711-720, 2007. https://doi.org/10.1590/S0006-87052007000400022

ROOSE, E. J. Use of the universal soil loss equation to predict erosion in West Africa. In: NATIONAL CONFERENCE ON SOIL EROSION, 1976, West Lafayette. Soil erosion: prediction and control: the proceedings... Ankeny: Soil Conservation Society of America, 1976. p. 60-74.

ROSS, J. L. S.; MOROZ, I. C. Mapa Geomorfológico do Estado de São Paulo. São Paulo: FFLCHUSP, 1997. Escala: 1:500.000.

SÃO PAULO (Estado). Mapa das Unidades Hidrográficas de Gerenciamento de Recursos Hídricos - UGRHI. São Paulo: IGC, 1996. Escala 1:1.000.000.

$\mathrm{SHI}, \mathrm{Z}$. H. et al. Modeling the impacts of integrated small watershed management on soil erosion and sediment delivery: A case study in the Three Gorges Area, China. Journal of Hydrology, Amsterdam, v. 438-439, p. 156-167, 2012. https://doi.org/10.1016/i.jhydrol.2012.03.016

SILVA, F. G. B. et al. Predição da perda de solo na Fazenda Canchim - SP (EMBRAPA) utilizando Geoprocessamento e o USLE 2D. Engenharia Sanitária e Ambiental, Rio de Janeiro, v. 15, n. 2, p. 141-148, 2010. https://doi.org/10.1590/S1413-41522010000200006

SOARES, P. C. et al. Ensaio de caracterização estratigráfica do Cretáceo no Estado de São Paulo: Grupo Bauru. Revista Brasileira de Geociências, São Paulo, v. 10, n. 3, p. 177-185, 1980. https://doi.org/10.25249/0375-7536.1980177185

USGS - United States Geological Survey. Imagem SENTINEL-2, sensor MSI, cena 22/K/FV de 07/02/2018, 14/03/2018, 24/03/2018 e 22/09/2018. Disponível em: https://earthexplorer.usgs.gov/. Acesso em: 16 dez. 2018.

VAN OOST, K.; GOVERS, G.; DESMET, P. Evaluating the effects of changes in landscape structure on soil erosion by water and tillage. Landscape Ecology, Dordrecht, v. 15, n. 3, p. 577-589, 2000. https://doi.org/10.1023/A:1008198215674

VAN ROMPAEY, A. et al. Modelling mean annual sediment yield using a distributed approach. Earth Surface Processes and Landforms, Chichester, v. 26, n. 11, p. 1221-1236, 2001. https://doi.org/10.1002/esp.275 
VAN ROMPAEY, A. et al. Modeling sediment yields in Italian catchments. Geomorphology, Amsterdam, v. 65, n. 1-2, p. 157-169, 2005. https://doi.org/10.1016/i.geomorph.2004.08.006

VAN ROMPAEY, A.; KRASA, J.; DOSTAL, T. Modelling the impact of land cover changes in the Czech Republic on sediment delivery. Land Use Policy, Oxford, v. 24, n. 3, p. 576-583, 2007. https://doi.org/10.1016/j.landusepol.2005.10.003

VERSTRAETEN, G. et al. Evaluating an integrated approach to catchment management to reduce soil loss and sediment pollution through modelling. Soil Use and Management, Cranfield, v. 18, n. 4, p. 386-394, 2002. https://doi.org/10.1079/SUM2002150

VERSTRAETEN, G. et al. Evaluating the impact of watershed management scenarios on changes in sediment delivery to rivers?. In: KRONVANG, B. (Ed.). The Interactions between Sediments and Water. Dordrecht: Kluwer Academic Publishers, 2003. p. 153-158. (Hydrobiologia, 494). https://doi.org/10.1007/978-94-017-3366-3 21

VERSTRAETEN, G. et al. The use of riparian vegetated filter strips to reduce river sediment loads: an overestimated control measure?. Hydrological Processes, Chichester, v. 20, n. 20, p. 4259-4267, 2006. https://doi.org/10.1002/hyp.6155

WISCHMEIER, W. H. A Rainfall Erosion Index for a Universal Soil-Loss Equation. Soil Science Society of America Journal, Madison, v. 23, n. 3, p. 246-249, 1959. https://doi.org/10.2136/sssaj1959.03615995002300030027x

WISCHMEIER, W. H.; JOHNSON, C. B.; CROSS, B. V. A soil erodibility nomograph for farmland and construction sites. Journal of Soil and Water Conservation, Ankeny, v. 26, n. 5, p. 189-193, 1971.

WISCHMEIER, W. H.; SMITH, D. D. Predicting rainfall erosion losses: a guide to conservation planning. Washington, DC: USDA, 1978. (Agriculture Handbook, 537).

Rainfall energy and its relationship to soil loss. Eos, Transactions, American Geophysical Union, Washington, DC, v. 39, n. 2, p. 285-291, 1958. https://doi.org/10.1029/TR039i002p00285

ZOCCAL, J. C. Adequação de erosões: causas, consequências e controle da erosão rural. Presidente Prudente: CODASP, 2007. (Caderno de Estudos em Conservação do Solo e Água, v. 1, n. 1).

Recebido em: 08/03/2020

Aceito para publicação em: 26/06/2020 